Artigo de Revisão

\title{
Hipervitaminose D em animais ${ }^{1}$
}

\author{
Paulo V. Peixoto ${ }^{2}$, Marcius A.P. Klem ${ }^{3}$, Ticiana N. França ${ }^{4}$ e Vivian A. Nogueira ${ }^{4 *}$
}

\begin{abstract}
Peixoto P.V., Klem M.A.P., França T.N. \& Nogueira V.A. 2012. [Vitamin D poisoning in animals.] Hipervitaminose D em animais. Pesquisa Veterinária Brasileira. 32(7):573594. Curso de Pós-Graduação em Medicina Veterinária, Universidade Federal Rural do Rio de Janeiro, Seropédica, RJ 23890-000, Brazil. E-mail: vivianmedvet@yahoo.com.br

Through revision of the literature, data are presented about vitamin D metabolism and the toxicological, clinical, biochemical, macro and microscopic, ultrastructural, immunhistochemical and radiographic aspects in animals of different species poisoned natural and experimentally by the vitamin. We aimed to show the existence of many lacunae in the knowledge of physiological and pathological tissue mineralization, especially regarding the hormonal metabolism of vitamin $\mathrm{D}$, and to alert for risk of the poisoning.
\end{abstract}

INDEX TERMS: Hypervitaminosis D, vitamin D poisoning, animals, pathology.

RESUMO.- Por meio de revisão da literatura, são apresentados dados referentes ao metabolismo da vitamina $\mathrm{D}$, bem como aos principais aspectos toxicológicos, clínicos, bioquímicos, macroscópicos, microscópicos, ultraestruturais, imuno-histoquímicos e radiográficos de animais intoxicados natural e experimentalmente por essa vitamina, em diferentes espécies. Este estudo objetiva demonstrar a existência de muitas lacunas no conhecimento sobre mineralização fisiológica e patológica, em especial na mediação hormonal do fenômeno, bem como alertar para os riscos de ocorrência dessa intoxicação.

TERMOS DE INDEXAÇÃO: Hipervitaminose D, intoxicação por vitamina $\mathrm{D}$, vitamina $\mathrm{D}$, animais, patologia.

\section{INTRODUÇÃo}

Considerando-se a massiva propaganda diária veiculada na mídia com o objetivo de vender produtos à base de vitaminas e microelementos que, pretensamente, melhorariam o desempenho físico e mental, as intoxicações por essas substâncias passaram a se constituir em considerável risco

\footnotetext{
${ }^{1}$ Recebido em 4 de janeiro de 2012.

Aceito para publicação em 27 de fevereiro de 2012.

Revisão com base na dissertação de mestrado junto ao Curso de Pós-Graduação em Medicina Veterinária,Universidade Federal Rural do Rio de Janeiro (UFRRJ).

${ }^{2}$ Departamento de Nutrição e Pastagem, UFRRJ, BR 465 Km 7, Seropédica, RJ 23890-000, Brasil. E-mail: peixotop@ufrrj.br

${ }^{3}$ Curso de Pós-Graduação em Medicina Veterinária, UFRRJ, BR 465 Km 7, Seropédica, RJ.

${ }^{4}$ Departamento de Epidemiologia e Saúde Pública, Instituto de Veterinária, Universidade Federal Rural do Rio de Janeiro, Seropédica, RJ. *Autor para correspondência: vivianmedvet@yahoo.com.br
}

para humanos. A situação pode ser considerada similar em relação aos animais, em especial, no que se refere às tentativas de se elevar a produtividade.

Por mais contraditório que possa parecer, a vitamina D é uma das substâncias mais tóxicas que se conhecem. Uma pessoa adulta, com função da paratireóide e sensibilidade à vitamina $\mathrm{D}$ normais, pode se intoxicar com a ingestão diária de aproximadamente 1,25 mg de vitamina D (Marcus 1996).

As calcinoses, enfermidades caracterizadas por extensa mineralização de tecidos moles, representam a principal manifestação clínico-patológica do envenenamento direto ou indireto por vitamina $\mathrm{D}$.

As intoxicações por plantas que contêm substâncias calcinogênicas são bem conhecidas em todo o mundo e ocorrem em diversas espécies animais (Mello \& Habermehl 1995). Essas enfermidades naturais, também denominadas calcinoses, mimetizam o envenenamento por vitamina D em quase todos os aspectos. Uma das alterações patológicas mais importantes que se observam nos animais com hipervitaminose D é o comprometimento do sistema cardiovascular, sobretudo pela mineralização das artérias.

A análise dos livros clássicos de Patologia Humana e Veterinária revela que essa intoxicação não parece estar convenientemente estudada e esclarecida. Em parte, tal se deve às complexas e, por vezes, obscuras relações que envolvem o metabolismo de cálcio, fósforo, vitamina $\mathrm{D}$, paratormônio (PTH), calcitonina (CT), hormônios tireoidianos e outros.

Este estudo foi realizado com os objetivos de coligir os principais dados relativos à vitamina $\mathrm{D}$, bem como abordar as particularidades relacionadas às diferentes formas 
de intoxicação por esse composto, no intuito de preveni-la e de fornecer subsídios que possam auxiliar no direcionamento de estudos futuros com essa substância.

\section{RESULTADOS}

\section{Aspectos históricos}

Antes da descoberta da vitamina D, no século XX, muitas crianças em regiões de zona temperada desenvolviam raquitismo. Alguns pesquisadores acreditavam que tal enfermidade era decorrente da falta de ar fresco e sol, enquanto outros a atribuíam à dieta. Em 1919, pesquisadores concluíram que a adição de óleo de fígado de bacalhau à dieta e a exposição à luz solar preveniam ou curavam o raquitismo; já nos animais, em 1924, observou-se que a irradiação ultravioleta de rações, assim como a irradiação do próprio animal, curavam esta enfermidade (Marcus 1996). McCollum e colaboradores, em 1925, haviam demonstrado que o "fator A lipossolúvel" em óleo de fígado de bacalhau continha dois compostos ativos, sendo um destes com ação anti-raquítica, o qual, em 1925, foi denominado "vitamina D" (Ewan 1996). Em 1930, a vitamina D foi considerada um milagre no tratamento do raquitismo e diversos alimentos começaram a ser suplementados com esse composto. Após a segunda guerra mundial, esse processo não foi adequadamente monitorado e uma quantidade excessiva foi acrescida em alguns tipos de leite, causando intoxicação em crianças e adolescentes. Este fato fez com que a adição fosse banida em muitos países, o que se mantém até os dias de hoje. Atualmente, os Estados Unidos é o único país que produz uma quantidade significativa de alimentos enriquecidos com vitamina D (Holick 2002).

\section{Formas e produção de vitamina D}

Existem diversos compostos de origem animal e vegetal com atividade metabólica de vitamina D. Dentre estes, os que apresentam maior atividade são colecalciferol (de origem animal, vitamina $\mathrm{D}_{3}$ ) e ergocalciferol (de origem vegetal, vitamina $\mathrm{D}_{2}$ ). 0 ergocalciferol difere do colecalciferol por possuir uma dupla ligação entre os carbonos $22 \mathrm{e}$ 23 e um grupo metil $\left(\mathrm{CH}_{3}\right)$ no carbono 24 (Fig.1).

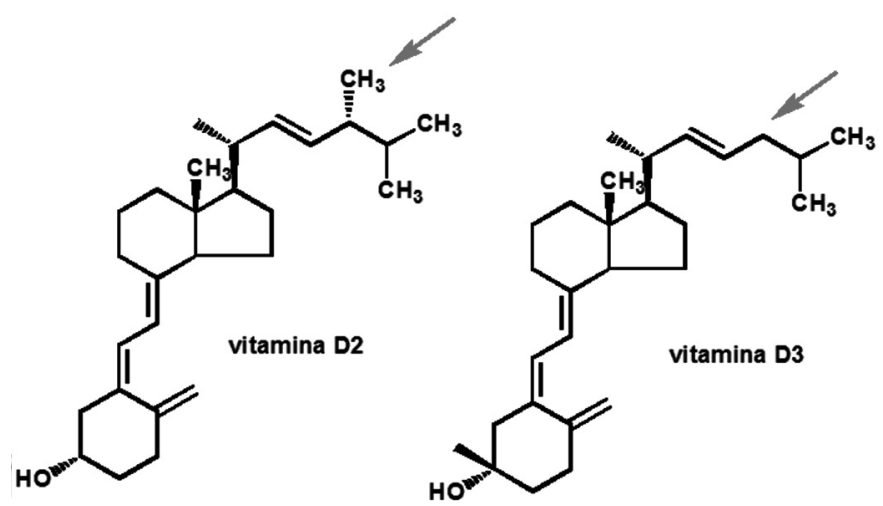

Fig.1. Estrutura química do ergocalciferol (vitamina $\mathrm{D}_{2}$ ) e do colecalciferol (vitamina $\mathrm{D}_{3}$ ). As duas formas diferem pela presença de uma ligação dupla adicional e um grupo metil incorporados à cadeia lateral da forma biológica $\mathrm{D}_{2}$ (seta).
Seres humanos e animais recebem vitamina D através da dieta com alimentos ou suplementos contendo colecalciferol e ergocalciferol ou a partir da produção endógena de colecalciferol.

0 ergocalciferol e o colecalciferol são produzidos a partir do ergosterol e do 7-deidrocolesterol, respectivamente (Holick 2004).

Produção de ergocalciferol. 0 ergosterol (pró-vitamina $D_{2}$ ), presente nos vegetais e fungos, é convertido em ergocalciferol (vitamina $\mathrm{D}_{2}$ ) sob ação de raios ultravioletas (reação de fotólise), que promove uma reestruturação intramolecular caracterizada por abertura do anel $\beta$ entre os carbonos 9 e 10, formação de uma dupla ligação entre os carbonos 10 e 19 e hidrogenação do carbono 9 (Holick 2004). Sob condições naturais, esta conversão ocorre em folhas mortas e também no processo de fenação; mostra-se mais eficaz quando realizada sob o sol do que dentro de celeiros ou por desidratação artificial. A irradiação ultravioleta em alimentos que contenham ergosterol é empregada para aumentar os valores de vitamina D (Islabão 1987).

Produção de colecalciferol. A vitamina $\mathrm{D}_{3}$ é sintetizada pela pele, por ação da radiação ultravioleta sobre a pró-vitamina $\mathrm{D}_{3}$, convertendo-a em pré-vitamina $\mathrm{D}_{3}$. Esta, por sua vez, sofre lise térmica, à temperatura corporal habitual e é transformada em vitamina $D_{3}$. Como incidência de raios UVB se dá principalmente sobre a epiderme, nessa camada faz-se a síntese de $80-90 \%$ da vitamina $\mathrm{D}_{3}$ nos adultos. Por outro lado, a exposição solar prolongada converte tanto a pré-vitamina $\mathrm{D}_{3}$ quanto a própria vitamina $\mathrm{D}_{3}$ em fotoisômeros inativos, o que evita o acúmulo excessivo destes metabólitos. Em nível celular, a vitamina $\mathrm{D}_{3}$ é sintetizada na membrana plasmática, lançada no espaço intercelular, ganha a corrente sanguínea e circula coligada à DBP (proteína ligante de vitamina D) (Holick et al. 1981).

Dependendo da pigmentação de melanina da pele e da exposição aos raios ultravioletas, a produção de colecalciferol pode suprir até $80 \%$ da vitamina D necessária em seres humanos (Kane \& Kumar 2000), sendo esta produção diretamente relacionada com a intensidade de exposição e inversamente relacionada com o grau de pigmentação de melanina da pele, a qual absorve os raios ultravioletas (Granner 1998). Protetores solares inibem a ação dos raios ultravioletas, prejudicando a produção de colecalciferol (Dawson-Hughes 1997). Seres humanos idosos se expõem menos à luz solar, têm a pele adelgaçada e menor concentração de 7-deidrocolesterol, o que resulta em menor produção de colecalciferol (Dawson-Hughes 1997).

Quanto maior a distância que os raios solares têm que percorrer para atingir a superfície terrestre, menor a intensidade dos raios ultravioletas, com consequente queda na conversão da pró-vitamina $\mathrm{D}_{3}$. Por isto, a conversão do 7-deidrocolesterol em colecalciferol é maior nos trópicos, no verão, ao meio-dia e em grandes altitudes. 0 leite de vacas em pastejo apresenta diferentes teores de vitamina $D$ entre inverno e verão. Estes teores variam, respectivamente, de 4,8 a 43,8 UI/litro no leite de vacas da raça Guernsey e de 3,1 a $28 \mathrm{UI} /$ litro no leite de vacas da raça Holandesa. Este conhecimento levou a produção de leite vitaminado, para consumo humano, com um mínimo de 400 UI/litro. 
Este enriquecimento do leite pode ser obtido irradiando-se o próprio leite ou fornecendo fontes de vitamina $D$ às vacas (Islabão 1987).

\section{Metabolismo}

Como as vitaminas $\mathrm{D}_{2}$ e $\mathrm{D}_{3}$ são similarmente metabolizadas, o termo vitamina $\mathrm{D}$ será aplicado às duas formas.

Absorção e transporte. A vitamina D endógena (colecalciferol), após ser produzida na pele, é transportada ao fígado, por via sanguínea, acoplada à DBP (Granner 1998, Kochupillai 2008).

A vitamina $D$ dietética (vitamina $D_{2}$ ou $D_{3}$ ) é absorvida no intestino delgado. 0 segmento intestinal em que há melhor absorção depende do veículo de administração da vitamina. A bile é essencial nesta absorção e o ácido desoxicólico é o principal componente da bile nesta função (Marcus 1996). Distúrbios gastrintestinais que prejudicam a mistura e a emulsificação de gorduras e diminuem o tempo de trânsito digestivo, reduzem a absorção de vitamina D. 0 envelhecimento em seres humanos também diminui esta absorção em aproximadamente 40\% (Dawson-Hughes 1997). A vitamina $D$ absorvida na dieta é transportada, em cerca de $85 \%$, ao fígado pelo sistema linfático (Islabão 1987) ou por via sanguínea junto à DBP (Granner 1998).

Ativação metabólica. 0 ergocalciferol e o colecalciferol, após duas hidroxilações, são convertidos em formas metabólicas mais ativas, o 1,25-diidroxiergocalciferol e o 1,25-diidroxicolecalciferol, respectivamente.

No fígado, a vitamina D é hidroxilada na posição 25 formando a 25-hidroxivitamina D ou 25(OH)D, por uma enzima hepática associada ao retículo endoplasmático, a calciferol-25-hidroxilase (Capen \& Rosol 1996, Kochupillai 2008) ou vitamina $D_{3}-25$-hidroxilase (Mayes 1998, De Luca 2004, Kochupillai 2008). De acordo com Granner (1998) esta hidroxilação ocorre no retículo endoplasmático, em uma reação que requer magnésio, NADPH, oxigênio molecular e um fator citoplasmático não caracterizado, com envolvimento de duas enzimas, redutase NADPH-dependente e citocromo P450. Este processo não é rigorosamente regulado, pois depende dos suprimentos dietéticos e cutâneos de vitamina $D_{3}$ e $D_{2}$ (Dawson-Hughes 1997) e também ocorre com pouca eficiência nos rins e intestinos (Granner 1998).

A $25(\mathrm{OH}) \mathrm{D}$ constitui a principal forma de vitamina D circulante e estocada no fígado, embora o tecido adiposo e os músculos esqueléticos também sejam importantes locais de armazenamento desse composto (Mayes 1998, Pfeifer et al. 2002, Ceglia 2008). Este metabólito é o precursor circulante da 1,25-diidroxivitamina D, 1,25(OH) 2 D (Capen \& Rosol 1996) ou calcitriol (Marcus 1996). Os mecanismos moleculares pelos quais a vitamina $\mathrm{D}$ age no músculo incluem os efeitos genômico e não-genômico. 0 primeiro inicia-se através da ligação da 1,25-diidroxivitamina $\mathrm{D}_{3}$ ao seu receptor nuclear, que resulta em mudanças na transcrição genética do RNAm e subsequente síntese protéica. 0 efeito não-genômico é rápido e mediado pela ligação da membrana com o receptor de vitamina D (VDR) (Pfeifer et al. 2002, Ceglia 2008). Embora haja referência à presença do VDR no músculo esquelético (Pedrosa \& Castro 2005), parece que os níveis de expressão desse receptor são baixos, uma vez que não são observadas lesões nesse tipo de tecido. Através da imuno-histoquímica, constatou-se que, na musculatura lisa das artérias e do sistema digestivo, parte das células têm VDR, enquanto outras não os possuem (Barros 2011).

Esta ativação se dá a partir de uma segunda hidroxilação que ocorre principalmente nos túbulos contornados proximais do rim, sob ação de um complexo enzimático presente nas mitocôndrias chamado de $1 \alpha$-hidroxilase, o qual é composto por uma oxidase de função mista que requer oxigênio molecular e NADPH como co-fatores; citocromo P450, uma flavoproteína, e a ferrodoxina também são componentes deste complexo enzimático (Marcus 1996, Kochupillai 2008).

Produção extra-renal de calcitriol ocorre na placenta, macrófagos (Marcus 1996) e ossos (Granner 1998). Em enfermidades que cursam com marcada proliferação de macrófagos ativados como a sarcoidose no homem e em outras doenças granulomatosas também pode haver produção de 1,25 diidroxicolecalciferol por essas células (Boon et al. 1993, Dawson-Hughes 1997). Situação semelhante tem sido descrita na paratuberculose de bovinos no Brasil (Driemeier et al. 1999).

"In vitro", células não-renais incluindo osso, placenta, próstata, queratinócitos, macrófagos, linfócitos T e células neoplásicas (neoplasias de pulmão, próstata e pele) podem converter a $25(\mathrm{OH}) \mathrm{D}$ em $1,25(\mathrm{OH})_{2} \mathrm{D}$, o calcitriol (Lehmann $\&$ Meurer 2003). Porém, muito pouco calcitriol é encontrado em animais não-prenhes e nefrectomizados (Granner 1998).

A conversão da $25(\mathrm{OH}) \mathrm{D}$ em $1,25(\mathrm{OH})_{2} \mathrm{D}$ é complexamente regulada. Neste controle é que incidem as maiores controvérsias e deficiências na literatura.

Assim como outros esteróides, o calcitriol está sujeito a estreito controle por retroalimentação. A atividade do complexo $1 \alpha$-hidroxilase aumenta na hipocalcemia e na hipofosfatemia, e cursa com níveis elevados de PTH (Granner 1998).

Estrógenos, progestágenos e andrógenos causam grande aumento da atividade da $1 \alpha$-hidroxilase em pássaros ovulando (Granner 1998). 0 papel que estes hormônios, ao lado da insulina, hormônio do crescimento e prolactina, desempenham no metabolismo da vitamina D em mamíferos, ainda é incerto (Granner 1998). Capen \& Rosol (1996) afirmam que há aumento da atividade da $1 \alpha$-hidroxilase pela prolactina, estradiol, lactogênio placentário e, possivelmente, pela somatotropina. Marcus (1996) sugere que a prolactina e o estrogênio estimulam esse complexo enzimático. Dawson-Hughes (1997) afirma que o estrogênio, o hormônio do crescimento, a prolactina, o lactogênio placentário, a CT e a insulina estimulam a $1 \alpha$-hidroxilase, porém seus papéis na produção diária de $1,25(\mathrm{OH})_{2} \mathrm{D}$ ainda não foram definidos.

A inibição da $1 \alpha$-hidroxilase ocorre tanto em quadros de hiperfosfatemia e hipercalcemia, quanto em caso de aumento dos níveis de 1,25(OH) 2 D (Dawson-Hughes 1997). Quando há inibição da $1 \alpha$-hidroxilase, a 25(OH)D é hidroxilada na posição 24 , por uma enzima mitocondrial presente nos túbulos renais, cartilagem, intestino e placenta, e forma a 
$24,25(\mathrm{OH})_{2} \mathrm{D}$, que é biologicamente inativa, cuja concentração está inversamente relacionada ao nível de $1,25(\mathrm{OH})_{2} \mathrm{D}$ (Mayes 1998). Capen \& Rosol (1996) descrevem que a $24,25(\mathrm{OH})_{2} \mathrm{D}$ é um metabólito menos ativo ou inativo na estimulação do transporte intestinal de cálcio, porém pode desempenhar papel na formação dos ossos, na eclodibilidade dos ovos e, juntamente com a $1,25(\mathrm{OH})_{2} \mathrm{D}$, no controle da retroalimentação negativa da secreção de PTH.

Um estudo com seis pacientes humanos intoxicados pela ingestão de leite superenriquecido com vitamina $D$ revelou que a regulação homeostática da $1 \alpha$-hidroxilase é, algumas vezes, suprimida por níveis muito elevados de $25(\mathrm{OH})$ $\mathrm{D}$; dois destes pacientes apresentaram níveis elevados de $1,25(\mathrm{OH})_{2} \mathrm{D}$. Há também o comprometimento da homeostase da vitamina D nas já referidas doenças granulomatosas, sobretudo na sarcoidose, decorrente da produção de $1,25(\mathrm{OH})_{2} \mathrm{D}$ pelos macrófagos, a qual não é regulada pelos fatores que modulam a síntese renal; ocorre hipercalcemia em 10\% dos pacientes com sarcoidose (Dawson-Hughes 1997).

\section{Efeitos biológicos da vitamina $D$}

Vitaminas $\mathrm{D}_{2}$ e $\mathrm{D}_{3}$ ativadas são, praticamente, equipotentes em seres humanos (Marcus 1996), porém, nas aves domésticas, a vitamina $D_{3}$ é 10 vezes mais potente que a vitamina $\mathrm{D}_{2}$ (Ewan 1996).

0 mecanismo de ação do calcitriol lembra o dos hormônios esteróides e dos tireoideanos; liga-se a receptores citoplasmáticos nas células-alvo e o complexo receptor-hormônio interage com o DNA para potencializar ou inibir a transcrição do gene (Marcus 1996).

Uma das principais funções da vitamina D está relacionada com a homeostasia do cálcio e do fósforo (DeLuca 2004, Kane \& Kumar 2005).

Intestino. A ação do calcitriol no intestino delgado ainda não está totalmente esclarecida. Sabe-se da indução, pelo calcitriol, de uma família de pequenas proteínas que se ligam ao cálcio (CBP - calcium binding protein). Acredita-se que a CBP facilita a passagem do cálcio para dentro das células epiteliais da mucosa. Esse conceito, porém, vem sendo questionado; postula-se que o calcitriol potencializa a captação endocitótica do cálcio da luz intestinal para vesículas no interior das células mucosas e que, posteriormente, estas vesículas se fundem aos lisossomos que transportam o cálcio para a membrana basal, onde é expulso para o meio extracelular (Marcus 1996).

Granner (1998) considera que os mecanismos pelos quais o calcitriol age na transferência de cálcio e fosfato através da mucosa intestinal não estão definidos e questiona o envolvimento ativo da CBP, visto que o translocamento de cálcio ocorre dentro de 1 a 2 horas após a administração de calcitriol, bem antes, portanto, do aumento da CBP em resposta ao mesmo. Dawson-Hughes (1997) relata, de forma pouco detalhada, que o calcitriol promove a absorção de cálcio e fósforo no intestino, ao atuar sobre os receptores nucleares das células da mucosa, iniciando a produção de proteínas ligadoras de cálcio e fósforo, as quais transportam estes íons através da mucosa.

Osso. No osso, o calcitriol é essencial, tanto para a formação, quanto para a reabsorção ósseas. Suas ações depen- dem dos níveis plasmáticos de cálcio (Kochupillai 2008).

Em situação de hipocalcemia, juntamente com o PTH, o calcitriol estimula a reabsorção óssea de cálcio e fósforo, possivelmente favorecendo a diferenciação dos osteoclastos a partir de monócitos (Kane \& Kumar 2005).

Por outro lado, a vitamina D é necessária para a mineralização normal da cartilagem epifisária e da matriz osteóide. Estes mecanismos ainda são incertos. Acredita-se que a função do calcitriol seja manter níveis plasmáticos de cálcio e fósforo supersaturados, contudo, o aumento na síntese das proteínas de ligação do cálcio no osso, osteocalcina e osteonectina, mediados pelo calcitriol na matriz osteóide, também podem desempenhar algum papel de significado (Kane \& Kumar 2005).

Segundo Dawson-Hughes (1997), a mineralização óssea é favorecida pela absorção aumentada de cálcio intestinal e pela ação reguladora na função dos osteoblastos. In vitro, o calcitriol atua sobre os receptores dos osteoblastos, aumentando a produção da fosfatase alcalina, da osteocalcina e de vários fatores do crescimento ósseo. Embora atuem juntos, níveis aumentados de $1,25(\mathrm{OH})_{2} \mathrm{D}$ também inibem a síntese e liberação de PTH.

A $1,25(\mathrm{OH})_{2}$ colecalciferol é 100 vezes mais potente que a $25(\mathrm{OH})$ colecalciferol, quanto à estimulação da reabsorção óssea in vitro (Capen \& Rosol 1996).

Outrora acreditava-se que a vitamina D interagia com receptores nucleares específicos nos pré-osteoclastos para iniciar a formação de osteoclastos maduros. Hoje, sabe-se que a $1,25(\mathrm{OH})_{2} \mathrm{D}$ inicia a mobilização de pré-osteoclastos através da interação destes com receptores nucleares específicos de vitamina D (VDR) nos osteoblastos e induz a expressão de RANKL (receptor activator of nuclear factor-kB ligand), um peptídeo de 317 aminoácidos da família do TNF expresso como uma citocina de membrana celular ou liberado como fator solúvel por diversas células, inclusive osteoblastos. O RANKL é conhecido também como ligante da osteoprotegerina (OPG). Os osteoclastos monocíticos precursores têm um receptor de membrana para RANKL, conhecido com RANK (localizado nos osteoclastos e células dendríticas) (Khosla 2001, Holick 2002, Kitazawa et al. 2003, Hofbauer et al. 2004, Kochupillai 2008). A interação entre RANKL e RANK ativa os sinais c-jun, NFk $\beta$ e serina/ treonina quinase $\mathrm{PKB} /$ Akt que estão relacionados com o processo de diferenciação, proliferação e apoptose celular. Em diversas patologias ósseas benignas e malignas, a administração da osteoprotegerina ou de RANK solúvel foi capaz de neutralizar o RANKL, prevenir a reabsorção e reduzir a perda óssea (Khosla 2001). A razão RANKL/OPG pode ser usada como marcador biológico de prognóstico em doenças como osteoporose, espondilite aquilosante, artrite reumatóide, tumores ósseos, osteólise associada a perdas protéicas e fraturas ósseas (Khosla 2001, Holick 2005).

A interação entre RANK do pré-osteoclasto com RANKL do osteoblasto sinaliza finalmente aos pré-osteoclasto para se tornarem osteoclastos multinucleados maduros. A vitamina D interage com os osteoblastos para aumentar a expressão de RANKL, osteocalcina, fosfatase alcalina e osteopontina (Holick 2002).

Rim. Nos rins, em associação com o PTH, o calcitriol reduz a excreção renal de cálcio (Dawson-Hughes 1997). Não 
há evidências substanciais de que esse composto possa participar na reabsorção renal de fósforo (Kane \& Kumar 2005). Durante a gestação, lactação e crescimento, os hormônios esteróides, prolactina, hormônio do crescimento $(\mathrm{GH})$ e o fator de crescimento insulina-símile (IGF-1) estimulam a síntese renal de $1,25(\mathrm{OH})_{2} \mathrm{D}$ com o objetivo de suprir as necessidades de cálcio que estão aumentadas (Holick 2007).

Interação da vitamina D com os hormônios tireoidianos A interação entre os hormônios tireoidianos e a $1,25(\mathrm{OH})_{2} \mathrm{D}$ é fundamental na formação dos osteoclastos. A triiodotironina (T3) induz a expressão do mRNA do RANKL em células primárias de osteoblastos e este efeito é amplificado na presença de $1,25(\mathrm{OH})_{2}$ D. A associação com tiroxina também induz a formação de osteoclastos. Os hormônios da tireóide são fundamentais para o metabolismo dos ossos, já que tanto a formação quanto a reabsorção ósseas são estimuladas quando há excesso de hormônios tireoidianos ou tireotoxicose. A tireotoxicose é considerada uma das principais causas de osteoporose secundária (Miura et al. 2002). Apesar dos termos hipertireoidismo e tireotoxicose serem frequentemente aplicados como sinônimos, o termo tireotoxicose refere-se a qualquer estado caracterizado por excesso de hormônio tireoidiano, produzido ou não pela tireóide. Nos casos de hipertireoidismo, as alterações ósseas foram caracterizadas como similares àquelas da osteodistrofia fibrosa, osteoporose e osteomalácia (Mosekilde et al. 1990), entretanto outros estudos demonstraram que elas diferem de todas essas patologias osteopênicas (Auwerx \& Bouillon 1986). No hipertireoidismo, há estímulo tanto da aposição quanto da reabsorção ósseas (Braverman \& Utiger 1996), mas a diminuição da massa óssea ocorre devido à superioridade do processo catabólico frente ao anabólico (Serakides 2001). Demonstrou-se ainda que a osteopenia em ratas hipertireóideas não é progressiva e que a resposta do osso aos hormônios tireoidianos varia de acordo com o indivíduo, com o sítio ósseo e com o tempo de administração da tiroxina (Serakides 2001, Ribeiro 2002). A maioria dos autores considera a osteoclasia como o principal processo de reabsorção óssea (Eriksen et al. 1986); entretanto Serakides (2001) é da opinião que a reabsorção induzida pelo hipertireoidismo se dá basicamente pela atividade dos osteócitos profundos, ou seja, pela osteólise osteocítica.

Indivíduos hipotireoideos possuem baixos níveis de vitamina $\mathrm{D}$ devido à má absorção intestinal ou incapacidade de ativação e, por isso, devem ter uma dieta que contenha no mínimo de 2000 UI desse composto por dia, o que evita o aparecimento de patologias ósseas. A diminuição da mineralização óssea na deficiência dos hormônios tireoidianos parece ser decorrente da redução dos valores plasmáticos de cálcio e fósforo (Bijslma 1983). Os hormônios tireoidianos também aumentam a absorção intestinal do fósforo mediada por gradiente de concentração dependente do sódio e, nos rins estimulam o co-transporte $\mathrm{Na}^{+} / \mathrm{Pi}$, proporcionando aumento da reabsorção tubular de fósforo (Cano et al. 1999).

A deficiência de vitamina $\mathrm{D}$ e as disfunções tireoidianas constituem os fatores de risco para a osteoporose (Ross 1996, Heaney 1996). O PTH, a CT e a vitamina D são os principais reguladores da homeostasia mineral, enquanto o estrógeno, os andrógenos, a tiroxina e a triiodotironina influenciam o metabolismo ósseo e controlam a reabsorção e a aposição ósseas (Hillard 1991, Raisz 1999, Gu et al. 2001). Verificou-se que agentes reabsortivos, tais como o $\mathrm{PTH}, 1,25(\mathrm{OH})_{2} \mathrm{D}_{3}$, TNF- $\alpha$ e as interleucinas, induzem a expressão de RANKL. 0 T3 induz a expressão de RANKL in vitro, mas esse efeito somente é amplificado quando se adiciona $1,25(\mathrm{OH})_{2} \mathrm{D}$ em meio de cultivo com osteoblastos, o que sugere a interação dos hormônios tireoidianos com a vitamina D no mecanismo de reabsorção óssea (Mosekilde et al. 1978). A deficiência dos hormônios tireoidianos reduz o metabolismo geral e afeta diretamente o recrutamento, a diferenciação, a maturação e o metabolismo das células responsáveis pela aposição, mineralização e reabsorção ósseas (Burkhart \& Jowsey 1967, Jowsey \& Detenbeck 1969, Mosekilde et al. 1978, Eriksen et al. 1986, Banavoc \& Koren 2000). A redução da aposição óssea, no hipotireoidismo, se dá por interferência direta (Burkhart \& Jowsey 1967), já que T3 e T4 estimulam a expressão de genes nos osteoblastos para a produção de colágeno e osteocalcina (Ross 1996, Varga et al. 1997). No hipotireoidismo, a absorção intestinal de cálcio é reduzida, já que os hormônios tireoidianos são necessários no transporte intestinal do cálcio e do fósforo mediado pelo $1,25(\mathrm{OH})_{2} \mathrm{D}$ (Cross \& Peterlick 1988, 1991). A importância dos hormônios tireoidianos no metabolismo e no turnover ósseos pode ser avaliada pela ocorrência de diversos tipos de alterações morfológicas no esqueleto de animais de diferentes espécies. Em humanos, são bem conhecidas as deformações ósseas associadas ao cretinismo determinado por deficiência de iodo. Silva et al. (1987) descreveram bócio e osteopetrose em fetos e recém-nascidos cujas mães (éguas) ingeriram, junto com o sal, quantidades extremamente elevadas de iodo. Cães jovens que ingerem dietas muito ricas em iodo desenvolvem, dentro de poucos meses, osteopatia metabólica determinada pelo hipotireoidismo (Castillo et al. 2001, Castillo 2002).

\section{Interação com vitamina A}

A vitamina A pode interferir na absorção, no transporte e na conversão da vitamina $D$ à sua forma ativa, além de estimular a degradação desse composto. A vitamina D aumenta a absorção e retenção de cálcio, enquanto o excesso de vitamina A causa reabsorção e descalcificação ósseas. Comprovou-se que a vitamina A inibe a capacidade de ação da vitamina D na cura do raquitismo (Rohde et al. 1999). Níveis elevados de vitamina A na dieta resultam em raquitismo, caracterizado por baixa taxa de crescimento, redução da placa epifisária da porção proximal da tíbia e marcada diminuição da densidade óssea (Metz et al. 1985). Cho et al. (1975) mostraram que a as manifestações clínicas relacionadas à hipervitaminose $\mathrm{A}$ em cães é reduzida quando administrada em associação com a vitamina D. Além disso, dieta rica em vitamina A previne a mineralização tubular renal e a depressão da taxa de crescimento associadas à hipervitaminose D (Metz et al. 1985).

De forma análoga, a hipovitaminose $\mathrm{D}$ pode ser potencializada pela ingestão de níveis elevados de vitamina A (David 1991). Essa hipótese é sustentada com base no significativo aumento do número de fraturas em huma- 
nos na Suécia (onde a exposição ao sol é menos frequente, com diminuição endógena da produção de vitamina D) e ingestão de níveis elevados de vitamina A (acima de 10.000 I.U). Estudos recentes sugerem que a ingestão de grande quantidade de vitamina A pelas mulheres e níveis séricos elevados de retinol nos homens podem estar correlacionados com o aumento do risco de osteoporose e fratura não traumática (Feskanich et al. 2002, Michaëlsson et al. 2003).

Portanto, embora fique evidente o antagonismo entre essas vitaminas, fenômenos a ele relacionados ainda não são bem compreendidos. Por exemplo, o excesso de vitamina A pode induzir osteoporose, mas também pode ser responsável por exostoses, como ocorre em gatos intoxicados por vitamina A contida em fígado de bovinos (Seawright et al. 1968). Esses animais desenvolvem a anquilose cervical deformante, determinada por exostoses confluentes nas vértebras cervicais e por vezes no occipital. Também em casos de "hyena disease", enfermidade que cursa com deformidades ósseas em bovinos, parece haver implicação da vitamina A ou das vitaminas A e D (Thompson 2008).

\section{Uso terapêutico}

Vitamina D e seus derivados, entre eles o diidrotaquiesterol (DTH), o 1 $\alpha$-hidroxicolecalciferol, o calcipotriol e o 22-oxa-calcitriol, são de importante interesse terapêutico e experimental (Marcus 1996). 0 uso terapêutico abrange, principalmente, a profilaxia e a cura do raquitismo nutricional, o tratamento do raquitismo e da osteomalácia metabólicos, do hipoparatireoidismo, a prevenção e o tratamento da osteoporose, da hipofosfatemia observada na síndrome de Fanconi (Marcus 1996), bem como os tratamentos da psoríase (Berth-Jones et al. 1993, Marcus 1996) e da mielofibrose (Wang 1992). A suplementação com níveis adequados de vitamina $\mathrm{D}$ também diminui a incidência de doenças cardiovasculares (Holick 2004, Zitterman 2006). Nos últimos anos, muito se tem testado "in vitro" a ação anti-neoplásica da vitamina D em tumores, como o retinoblastoma (Wagner et al. 2003), o carcinoma prostático (Qiao et al. 2003) e até mesmo "in vivo", como o osteossarcoma experimentalmente implantado em ratos gnotobióticos (Barroga et al. 2000). Uma vez que receptores de vitamina $D$ estão presentes em linfócitos T e B e macrófagos ativados, a prevenção de doenças auto-imunes, incluindo diabetes tipo I, artrite reumatóide e esclerose múltipa têm sido possível através da suplementação com esse composto (Holick 2004).

Acreditava-se que concentrações elevadas de 25(OH) D implicavam em maior absorção de cálcio (Heaney et al. 2003, Hansen et al. 2008), baixa incidência de hiperparatiroidismo secundário (Malabanan et al. 1998) e de fraturas ósseas (Bischoff-Ferrari et al. 2004). Em 2005, Dawson-Hughes et al. estimaram que valores séricos iguais ou superiores a $30 \mathrm{ng} / \mathrm{mL}(75 \mathrm{nmol} / \mathrm{L})$ de 25(OH)D eram essenciais para o bom funcionamento do osso.

Recentemente, dois estudos foram realizados com o intuito de avaliar os efeitos dos níveis séricos de 25(OH)D acima de $30 \mathrm{ng} / \mathrm{mL}$ após terapia com vitamina D. Os achados foram surpreendentes. Em um deles, não houve diminuição na concentração de PTH ou na reabsorção óssea (Aloia et al. 2010) e, no outro, níveis de 25(OH)D superiores a 30 $\mathrm{ng} / \mathrm{mL}$ causaram maior número de fraturas ósseas (Sanders et al. 2010). Após análise dos resultados, pesquisadores do Instituto de Medicina dos Estados Unidos concluíram que valores iguais ou acima de $20 \mathrm{ng} / \mathrm{mL}$ de $25(\mathrm{OH}) \mathrm{D}$ são adequados e que níveis séricos acima de $30 \mathrm{ng} / \mathrm{mL}$ não são necessários para todos os indivíduos (Hansen 2011).

Utilização imprópria ou desnecessária. No meio rural brasileiro, há uma espécie de consenso sobre a necessidade ou importância de utilizarem-se medicamentos injetáveis que têm como base as vitaminas A, D e E. Boa parte dos veterinários que atuam no campo tem por hábito prescrever ADE injetável, em especial para vacas, sob o argumento de que haveria necessidade dessa suplementação no caso do capim estar seco ou amarelado. A vitamina A tem sido administrada, simultaneamente, com a vitamina D com o propósito de obter uma preparação equilibrada entre ambas e, em altas doses, com o objetivo de minimizar os efeitos tóxicos da ingestão excessiva de vitamina $D$ (Metz et al. 1985). A nosso ver, essa prática não faz sentido, uma vez que, no Brasil, não há necessidade de suplementar bovinos, em regime de pastagem, com vitamina $A$.

\section{Toxicologia}

Intoxicações por vitamina D ou por seus derivados são descritas em todo o mundo em diversas espécies, inclusive em seres humanos. Estas intoxicações ocorrem das mais variadas formas, em decorrência do uso destas substâncias como suplementos vitamínicos, como substâncias terapêuticas, como veneno (rodenticidas) e ainda em animais que, porventura, alimentem-se com plantas que contenham substâncias calcinogênicas análogas à vitamina $\mathrm{D}$, como Nierembergia veitchii, Solanum malacoxylon, Solanum torvum, Cestrum diurnum e Trisetum flavescens (Döbereiner et al. 1971, Barros et al. 1981, Riet-Correa et al. 1981, Barros et al. 1992, Riet-Correa et al. 1993, Barros et al. 1996, Tokarnia et al. 2000, McGavin \& Zachary 2007).

Em humanos foi descrita intoxicação por vitamina D em uma família que ingeria alimentos cozidos com óleo de nozes contendo 5 milhões de unidades de vitamina $\mathrm{D}_{3} / \mathrm{ml}$; todos apresentaram sintomas de hipercalcemia. Os níveis plasmáticos do pai e da mãe foram, respectivamente, 55 e $60 \mathrm{UI} / \mathrm{ml}$; os valores normais oscilam de 0 a 1,6 UI/ml. Onze anos depois todos os três pacientes estavam bem, porém, à biópsia renal, um deles apresentou nefrocalcinose persistente (Down et al. 1979). Em outro relato, quatro crianças se intoxicaram com vitamina $\mathrm{D}\left(7,5 \mathrm{mg}\right.$ de vitamina $\left.\mathrm{D}_{3}\right)$, por via oral, em 4 semanas (a dose padrão para a profilaxia de raquitismo é de 400 UI diária no primeiro ano de vida). Hipercalcemia, hipercalciúria, nefrocalcinose medular e hematúria devido a passagem de um cálculo foram observadas (Hoppe et al. 1992). Dois lactentes (2 e 18 meses de idade), de famílias diferentes, foram intoxicados por vitamina $\mathrm{D}$ devido a erro na administração por seus familiares. Um recebeu 9.000.000 I.U. em 15 dias e o outro 4.200.000 U.I. em 7 dias. Os sinais clínicos foram similares, náusea, vomito, poliúria, desidratação, redução do tônus muscular, hipercalcemina, hipercalciúria e distúrbios na habilidade de concentração renal (Molina et al. 1984).

Nos Quadros 1 a 15 estão detalhados casos de intoxicação por vitamina $\mathrm{D}$ em diversas espécies. 


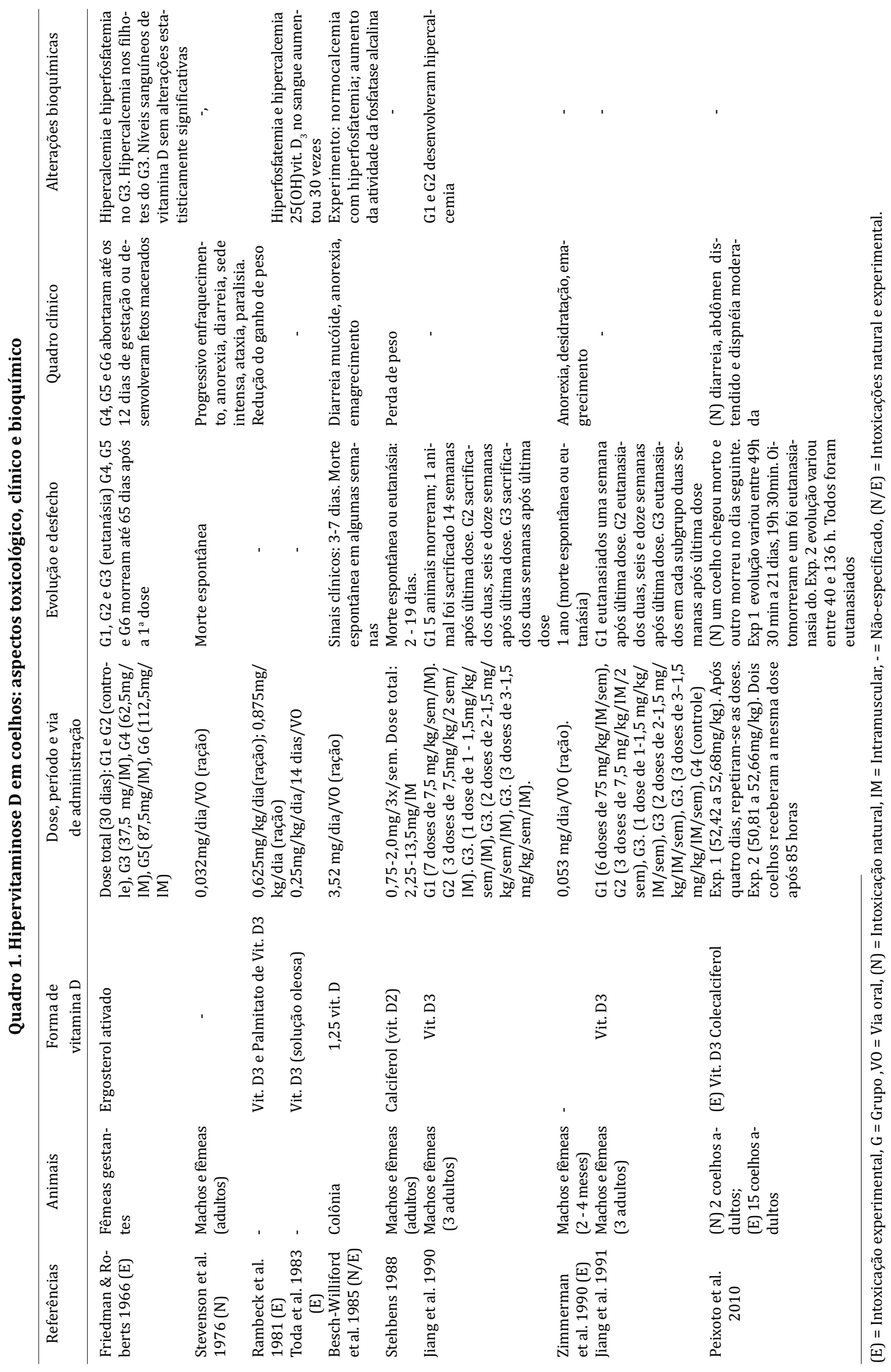


Quadro 2. Hipervitaminose D em coelhos: aspectos macroscópico e microscópico

\begin{tabular}{cc}
\hline Referências & Macroscopia \\
\hline $\begin{array}{c}\text { Friedman \& Roberts } \\
1966 \text { (E) }\end{array}$ & $\begin{array}{c}\text { Aorta. G4, G5 e G6 com depressão irregular na íntima. } \\
\text { G3 com lesões similares, porém, menos marcadas e mais } \\
\text { pronunciadas na aorta proximal }\end{array}$
\end{tabular}

Stevenson et al. 1976 Rins. Aumentados e com córtex mosqueado; minerali(N) zação do córtex ao corte
Rambeck et al. 1981

(E)

Toda et al. 1983 (E)

Besch-Williford et al. 1985 (N/E)

Stehbens $1988(\mathrm{E})$

Jiang et al. 1990 (E)
Aorta e rins. Mineralização; os coelhos que receberam doses mais altas $(0,875 \mathrm{mg} / \mathrm{kg})$ apresentaram depósitos de cálcio mais extensos

\section{Útero e musculatura lisa gastrintestinal. Mineraliza-} ção. Rim e miocárdio. Manchas castanhas

Aorta. Calcificação na porção descendente e no arco aórtico, mais marcada na aorta torácica e eventualmente em toda a aorta abdominal; inicialmente os depósitos eram pequenos e, muitas vezes, orientados longitudinalmente; depois se formaram placas separadas com aparência de "pele de crocodilo"; superfície da aorta áspera e com diâmetro muito aumentado. Tronco da artéria pulmonar. Apresentou calcificação em casos severos. Carótidas. Calcificação em casos mais graves e os locais de arteriotomia tinham menor predileção à calcificação. Artérias renais. Mais flá-cidas que o normal à dissecação
Zimmerman et al. $1990(\mathrm{E})$
Aorta e grandes artérias. Irregularidade na superfície da íntima e da adventícia, em alguns até o tronco aórtico-entérico. Rins. Áreas multifocais castanho-acinzentadas por todo o córtex
Aorta. G4, G5 e G6 com mineralização e focos de degeneração e necrose na média. G3 com lesões similares, porém, menos marcadas e mais pronunciadas na aorta proximal

Coração. Artérias médias do miocárdio com depósitos de Ca mais evidentes na média do que na íntima, geralmente $1 / 3$ a 1/2 da circunferência; artérias pequenas e arteríolas com total espessamento e calcificação da íntima. Ao redor destes vasos há degeneração das fibras do miocárdio com depósito de Ca. Pequenos depósitos de Ca no músculo, sem correlação com as arteríolas. Aorta. Grandes depósitos de Ca na média. Bexiga, fígado, cápsula da adrenal, baço e pequenos vasos adjacentes ao pâncreas. Mineralização na média das arteríolas. Traquéia, ovários, ovidutos e útero. Artérias com mineralização; extenso depósito de Ca no miométrio. Estômago. Depósito de Ca espalhado por toda mucosa gástrica (mais no terço médio); muscular da mucosa com depósito de Ca onde havia contato com arteríolas da submucosa. Rins. Severamente, mas não uniformemente, mineralizados; depósitos de Ca foram mais comuns no córtex e terço médio da medula; glomérulos, túbulos e arteríolas foram afetados. Pulmão. Pneumonia intersticial de vários graus; depósitos de Ca em artérias pulmonares, músculo liso dos brônquios e bronquíolos, mucosa brônquica e nos septos interalveolares de diversos coelhos. Osso. e nos septos interalveolares de diversos coelhos. Osso. Material basofílico principalmente nas trabéculas da medula óssea, periósteo e superfície do endósteo. Este material tem aparência de fibrose e contém células (provavelmente osteoblastos)

Aorta. Pronunciada necrose das células

Mineralização do endotélio vascular e do tecido fibroelástico de todas as vísceras, bem como em miócitos cardíacos e na musculatura lisa

Os coelhos do G3 não apresentaram alterações. Ossos. Todos os coelhos do G1 e G2 demonstraram vários graus de calcificação nas epífises, metáfises e diáfises; a severidade das lesões variou muito dentro de cada grupo. Áreas de osteoesclerose difusa correspondiam a trabéculas normais, ou somente ligeiramente adelgaçadas; a estrutura trabecular e orientação eram normais e os osteócitos bem visíveis; inversamente, difusa calcificação recobria as trabéculas. Em muitos casos, a cavidade medular era recoberta com calcificação. A distribuição da calcificação era desigual na metáfise e epífise. A densa linha metafiseal vista na radiografia correspondia com trabéculas rigorosamente arranjadas longitudinalmente entremeadas com calcificação. Nos locais da diáfise próximos à metáfise, que apareciam mais densos, correspondiam à neoformação óssea periosteal com depósitos de calcificação. No córtex ósseo original, havia cavernas múltiplas causadas por reabsorção osteoclástica. Uma lâmina espessada de calcificação margeava a parede das cavernas. Em casos severos, as cavernas estavam totalmente preenchidas com calcificação. Calcificação do osso periosteal recentemente formado contribuía para a reação periosteal linear vista na radiografia. Carpos, tarsos e patelas apre sentaram alterações histológicas similares

Aorta e miocárdio. Extensa mineralização da túnica média da aorta e de arteríolas do miocárdio, com áreas de espessamento nestes casos. Rins. Mineralização da membrana basal dos túbulos renais e glomérulos, os quais foram envolvidos por extensa fibrose intersticial. Pulmão, útero, estômago, cápsula e trabéculas do baço. Mineraização de arteríolas

$\overline{(E) ~=~ I n t o x i c a c ̧ a ̃ o ~ e x p e r i m e n t a l, ~}(\mathrm{~N} / \mathrm{E})$ = Intoxicações natural e experimental, $(\mathrm{N})$ = Intoxicação natural, $\mathrm{G}=$ Grupo. 
Quadro 2 (cont.). Hipervitaminose D em coelhos: aspectos macroscópico e microscópico

\begin{tabular}{|c|c|}
\hline Referências & Macroscopia \\
\hline Jiang et al. 1991 (E) & - \\
\hline $\begin{array}{l}\text { Cramer et al. } 1998 \text { (E) } \\
\text { Peixoto et al. } 2010 \\
\text { (N/E) }\end{array}$ & $\begin{array}{l}\text { Rins. Nefrocalcinose. } \\
\text { (N) Coração. Leve hidropericárdio, marcada dilatação } \\
\text { de câmaras, mineralização na superfície do endocár- } \\
\text { dio do átrio esquerdo e nas valvas mitral e tricúspide. } \\
\text { Artérias aorta, carótidas, femorais e renais. Íntima } \\
\text { irregular e formação de placas esbranquiçadas. Havia } \\
\text { também acentuada ascite. Fígado. Aspecto de noz-mos- } \\
\text { cada. Baço. Congesto } \\
\text { (E) Coração. Áreas esbranquiçadas na mitral e no endo- } \\
\text { cárdio do átrio esquerdo. Hipertrofia de ventrículo es- } \\
\text { querdo e dilatação de ventrículo direito. Aorta com mi- } \\
\text { neralização mais pronunciada na porção torácica. Ar- } \\
\text { térias carótidas, renais e da parede do estômago tam- } \\
\text { bém mineralizadas. Havia ainda áreas esbranquiçadas } \\
\text { de mineralização na super fície peritoneal. Pleura pa- } \\
\text { rietal. Áreas de mineralização. Estômago. Edema sub- } \\
\text { seroso. Áreas de mineralização sob a serosa. A muco- } \\
\text { sa gástrica apresentava áreas avermelha das e eleva- } \\
\text { das. Rim. Discreta linha esbranquiçada na medula mar- } \\
\text { geando a junção córtico-medular, congestão, pontos es- } \\
\text { branquiçados próximos à pelve e junção córtico-me- } \\
\text { dular mais esbranquiçada }\end{array}$ \\
\hline
\end{tabular}

G3 e G4 não apresentaram alterações. G1 e G2: Ossos. Nos locais de reabsorção subperiosteal demonstrou-se vascularização periosteal dilatada e tortuosa, proliferação ativa e espessamento do periósteo fibroso, com invasão do córtex ósseo. Nos locais de proliferação óssea periosteal alterações vasculares semelhantes eram vistas nas trabéculas recém-formadas, muitas vezes recobertas com calcificação. Ao longo dos vasos dilatados e proliferados, havia extensa reabsorção óssea, com formação de cavernas no córtex ósseo e dilatação dos canais de Havers. Estas cavernas, às vezes, estavam preenchidas com calcificação

Microscopia óptica. Os achados foram similares entre os coelhos das intoxicações natural e experimental, contudo eram mais marcados na intoxicação natural. Aorta. Mineralização na camada muscular e na íntima, por vezes, acompanhada por metaplasias óssea e condróide Um animal apresentou acentuada tumefação das fibras musculares. Coração. Mineralização, caracterizada por depósitos granulares ou pequenas placas basofílicas, no endocárdio e nas artérias, por vezes acompanhada por metaplasia condróide e/ou óssea, no miocárdio pericoronariano e em artérias coronárias. As valvas átrioventriculares encontravam-se espessadas por substância fundamental levemente basofílica, homogênea, associada, em apenas um caso, à mineralização. Proliferação de células mononucleares com aspecto de macrófagos foi observada com frequência no interstício. Pulmão. Variável grau de mineralização nas paredes alveolares e nas diversas camadas de brônquios e bronquíolos, inclusive epitélio. Havia, também, espessamento e mineralização de artérias e arteríolas, congestão e enfisema alveolar. No interstício foi verificada metaplasia osteocondróide, com presença de osteoclastos e proliferação de células mononucleares. Um animal, adicionalmente, apresentou peribronquiolite, trombose, leucocitoestase e pneumonia intersticial. Traquéia. Mineralização e osseificação da cartilagem e de vasos da submucosa. Estômago. Mineralização mais acentuada na camada muscular, embora depósitos de mineral também estivessem presentes nas células epiteliais da mucosa e nas células parietais, e entre elas, no interstício da submucosa, na serosa e nos vasos das diversas camadas. Adicionalmente foram observados congestão e edema da mucosa e da submucosa, assim como proliferação intersticial de células mononucleares semelhantes a macrófagos e atrofia das fibras da camada muscular adjacente às áreas mineralizadas. Rins. No córtex, evidente mineralização foi verificada nas cápsulas de Bowman, na membrana basal e no epitélio dos túbulos; eventualmente, em artérias e no interstício, a mineralização ocorria associada a edema e a fibrose intersticial. Havia ainda congestão, dilatação dos espaços de Bowman e de túbulos uriníferos com aumento do filtrado glomerular. Em um animal aparentemente havia osseificação incipiente da cápsula de Bowman. Intestinos. Lesões similares às do estômago, porém bem menos marcadas. Fígado. Grandes focos de vacuolização de hepatócitos e proliferação de células das vias biliares, congestão com degeneração hepatocelular secundária e evolução para lise. Observaram-se ainda edema, mineralização e osseificação das artérias da vesícula biliar; mineralização e osseificação vascular na língua; mineralização de vasos da glândula salivar; artérias do útero com mineralização na muscular, edema na íntima e redução do lúmen, além de edema difuso na parede uterina; moderada quantidade de hemossiderina, mineralização de artéria centro-folicular e congestão do baço

Microscopia eletrônica. Aorta e parede do estômago. Transformação das células musculares lisas, do tipo contrátil, em células do tipo sintético, representada por incremento do retículo endoplasmático rugoso e do sistema de Golgi, acentuada diminuição dos elementos contráteis, perda parcial ou total da membrana basal e presença de vesículas pinocíticas. As lâminas elásticas exibiam delicados cristais na periferia ou apresentavam-se parcialmente calcificadas. Havia extensas áreas de mineralização intersticial, com formação de estruturas concêntricas, tanto nas artérias como na muscular e mu cosa do estômago. Macrófagos ativados foram frequentemente vistos nas áreas próximas aos focos de mineralização

$\overline{(E) ~=~ I n t o x i c a c ̧ a ̃ o ~ e x p e r i m e n t a l, ~}(\mathrm{~N} / \mathrm{E})$ = Intoxicações natural e experimental, $(\mathrm{N})$ = Intoxicação natural, $\mathrm{G}=$ Grupo. 
Quadro 3. Aspecto radiográfico da hipervitaminose D em coelhos

Jiang et al. 1990 (E) G3 não apresentaram alterações radiográficas. Ossos. G1 e G2 com osteoesclerose sendo as alterações mais marcadas no G1, contudo, as lesões variaram consideravelmente dentro de cada grupo, sendo que, por vezes, coelhos do G2 apresentavam lesão mais marcada que os do G3. Osteoesclerose difusa era vista na radiografia como tecido ósseo esponjoso denso e homogêneo em metáfise e epífise com perda de padrão trabecular e denso córtex espessado. Radiograficamente havia trabéculas grosseiras, ou uma superfície óssea articular espessada com relativa diminuição da radio-pacidade no centro. As epífises e metáfises, às vezes, manifestavam áreas localizadas de aumento de densidade. Em muitos casos, uma densa banda (linha) metafiseal foi observada (que corresponde às trabéculas arranjadas longitudinalmente entremeadas com calcificação na microscopia). A medular óssea diafiseal mostrou mudanças menos severas, em muitos casos apresentavam pontos densos dispersos. A diáfise, próxima à metáfise, mostrava densidade aumentada (corresponde a neoformação periosteal com depósitos de calcificação na microscopia). Reação periosteal linear correspondente a calcificação depositada no osso periosteal recentemente formado. Carpos, tarsos e patelas também apresentaram densidade aumentada

Zimmerman et al. Aorta e rim. Mineralização.

$1990(\mathrm{E})$

Jiang et al. 1991 (E) Foram observadas alterações em G1 e G2. Ossos longos e costelas com reabsorção subperiosteal, linhas lucentes intracorticais, neoformação ósSea periosteal. Ossos longos e vértebras com bandas densas meta e epifisiárias. A reabsorção óssea correspondia à cortical óssea porosa vista na radiografia, entretanto, osso era denso visto somente com severa calcificação

(E) = Intoxicação experimental, G = Grupo.

Quadro 4. Hipervitaminose D em caprinos: aspectos toxicológico, clínico e bioquímico

\begin{tabular}{|c|c|c|c|c|c|c|}
\hline Referências & $\begin{array}{l}\text { Idade dos } \\
\text { animais }\end{array}$ & $\begin{array}{c}\text { Forma de } \\
\text { Vitamina D }\end{array}$ & $\begin{array}{c}\text { Dose, período e via } \\
\text { de administração }\end{array}$ & $\begin{array}{c}\text { Evolução e } \\
\text { desfecho }\end{array}$ & Quadro clínico & Alterações bioquímicas \\
\hline $\begin{array}{l}\text { Singh \& Prasad } \\
1989(\mathrm{E})\end{array}$ & 3-12 meses & Colecalci-ferol & $\begin{array}{l}\text { G1 7,5 mg/animal/sem/IM } \\
\text { (2 meses). G2 7,5 mg/ani- } \\
\text { mal/sem/IM ( } 4 \text { meses). G3 } \\
\text { 7,5 mg/animal/sem/IM ( } 8 \\
\text { meses) }\end{array}$ & $\begin{array}{l}\text { Sacrificado logo } \\
\text { após o término } \\
\text { da administra- } \\
\text { ção da Vit. D3 }\end{array}$ & $\begin{array}{l}\text { Depois de um mês apresen- } \\
\text { sentavam-se deprimidos, } \\
\text { com pelagem áspera, inape- } \\
\text { tência, polidipsia, poliúria } \\
\text { e diarreia. Com o tempo o } \\
\text { quadro clínico era cada vez } \\
\text { mais severo, sobretudo nos } \\
\text { animais jovens }\end{array}$ & $\begin{array}{l}\text { Hipercalcemia durante os } 4 \text { pri- } \\
\text { meiros meses. Fósforo perma- } \\
\text { neceu alto e atingiu o pico no } \\
4^{\circ} \text { mês. Colesterol com signifi- } \\
\text { cativo aumento nos primeiros } \\
3 \text { meses }\end{array}$ \\
\hline
\end{tabular}

$\overline{(E) ~=~ I n t o x i c a c ̧ a ̃ o ~ e x p e r i m e n t a l, ~ G ~=~ G r u p o, ~ I M ~=~ I n t r a m u s c u l a r . ~}$

\section{Hipervitaminose D: mineralização distrófica ou metas- tática?}

Classicamente, as mineralizações patológicas vêm sendo divididas em distrófica e metastática. A do tipo distrófica ocorre quando há deposição de minerais em tecidos submetidos a qualquer tipo de lesão necrótica, degenerativa ou inflamatória. No caso de mineralização metastática haveria precipitação de sais de cálcio em decorrência da concentração persistentemente elevada deste mineral no sangue, sem que os tecidos afetados tenham sofrido qualquer lesão prévia (Jones et al. 2000, Cheville 2004, Werner 2010).

A maior parte da literatura destinada ao ensino da Patologia Geral e/ou Patologia Veterinária menciona que a principal alteração tecidual nas intoxicações pela vitamina D e pelas plantas calcinogênicas seria a calcificação metastática. Segundo muitos autores, os efeitos deletérios da intoxicação pela vitamina D se devem à hipercalcemia, que resulta da maior absorção intestinal (Jones et al. 2000, Cheville 2004, Werner 2010) e da redução da excreção de cálcio pela urina (Jones et al. 2000).

Sabe-se que, nos casos de intoxicação experimental por Solanum malacoxylon em bovinos que receberam 0,17 e $0,16 \mathrm{~g} / \mathrm{kg} / \mathrm{semana}$ da planta durante 16 e 54 semanas, respectivamente, houve hipercalcemia transitória, ou seja, o nível de cálcio sérico estava um pouco mais elevado (16\%) 24 horas após a administração da planta, mas encontrava-se dentro da normalidade quando avaliados duas sema- nas após a ingestão de $S$. malacoxylon (não se sabe, porém exatamente quando teve início a queda da calcemia, já que as colheitas de sangue para exame eram feitas a cada 14 dias). Adicionalmente, verificou-se que não houve diferença significativa na calcemia entre os bovinos mantidos em regiões do Pantanal Matogrossense onde ocorre a doença e aqueles oriundos de regiões em que a doença não existe (Döbereiner et al. 1971). De forma análoga, na intoxicação experimental por Nierembergia veitchii em ovinos, conduzida por Riet-Correa et al. (1993), houve leve hipercalcemia (em relação ao teor de cálcio sérico aferido antes da ingestão da planta , aprox. 8,2 e 8,6mg/dL) dentro das primeiras 48 horas, porém, depois desse período houve leve oscilação dos níveis de cálcio, de aprox. 9,3 a 10,8mg/dL, dentro de um patamar um pouco acima da calcemia medida no dia zero; contudo em nenhum momento, os níveis máximos de cálcio sérico dos ovinos submetidos à experimentação, por pelo menos 48 dias $(10,2$ e $10,8 \mathrm{mg} / \mathrm{dL})$ passaram daqueles considerados como normais para a espécie $(11,5$ e 12,8mg/dL) (Kaneko 1997); ou seja, não parece haver evidências de que a calcemia tenha um papel de significado na mineralização dos tecidos.

De fato, de acordo com Barros (2011), em animais intoxicados por vitamina $D$, a deposição de cálcio nos tecidos não está diretamente ligada à hipercalcemia; essa idéia, disseminada inclusive em livros-texto, está equivocada e ainda tem como base a classificação de Virchow, já questionada por Seifert \& Hentig (1967). Coelhos lactentes, por 
Quadro 5. Hipervitaminose D em caprinos: aspectos macroscópico e microscópico

\begin{tabular}{|c|c|}
\hline Referências & Macroscopia \\
\hline Singh \& Prasad 1989 (E) & $\begin{array}{l}\text { Aorta. G1 (3/5 dos animais) com lesões na aorta toráci- } \\
\text { ca; G2 (3/5 dos animais) e G3 (4/5 dos animais) com } \\
\text { lesões na aorta torácica e abdominal. As lesões escle- } \\
\text { róticas eram elevadas, circulares a alongadas, ásperas, } \\
\text { irregulares, branco-acinzentadas, de vários tamanhos } \\
\text { e espalhadas na íntima. As aortas muito afetadas fica- } \\
\text { ram ásperas e rígidas; a íntima interna era coberta por } \\
\text { placas }(40-60 \%)\end{array}$ \\
\hline Singh \& Prasad 1990 (E) & $\begin{array}{l}\text { Coração. Hidropericárdio; pequenos depósitos (cabeças } \\
\text { de alfinete a lentilhas) calcários nas valvas mitral e sig- } \\
\text { móide. Aorta. Placas fibro-calcificadas de vários tama- } \\
\text { nhos na superfície intimal e em seus ramos. Pulmão. } \\
\text { Áreas de manchas branco-acinzentadas arenosas no } \\
\text { bordo inferior de lobos apicais em animais de todos os } \\
\text { grupos; áreas de congestão, enfisema, colapso e conso- } \\
\text { lidação nas áreas branco-acinzentadas. Rins. Edema- } \\
\text { tosos e mosqueados, arenosos ao corte; medular pou- } \\
\text { co congesta e início de hidronefrose, especialmente a- } \\
\text { nimais do G2 e G3. Cérebro Congestão e edema }\end{array}$ \\
\hline
\end{tabular}
Microscopia óptica, microscopia eletrônica e imunohistoquímica

$2 / 3$ dos animais $(10 / 15)$ desenvolveram lesões arterioescleróticas. Espessamento da íntima delineada por massiva necrocalcificação medial. 0 espessamento intimal consiste de proliferação de fibras colágenas e células de músculo liso; reduplicação e frag mentação da lâmina elástica interna.

Quanto mais prolongado era o tratamento, mais severas eram as lesões

Pulmão. Moderado a marcado espessamento dos septos alveo lares; vários graus de mineralização do epitélio bronquiolar, cartilagem e musculatura da parede alveolar; metaplasia óssea na cartilagem bronquial e espessamento alveolar acompanhado de infiltrado mononuclear em raras cabras do G3; arteríolas pleurais também se apresentaram ingurgitadas e calcificadas. Rins. Vários graus de dilatação tubular; degeneração/necrose tubular e glomerular; mineralização de vasos sangüíneos intertubulares, cápsula de Bowman e túbulos; congestão de vasos intertubulares e tufos glomerulares, atrofia de tufos glomerulares e áreas focais de infiltrado mononuclear; grande número de microcálculos espalhados por toda a microsecção. Fígado. Pronunciada necrose/degeneração de áreas periportais/pericentral; em muitos casos, hiperatividade das células de Kupffer com áreas de infiltrado mononuclear; fibras colágenas proeminentes em áreas periportais, exibindo calcificação e hiperplasia de dutos biliares. Tireóide. Mudanças simulando o bócio; espessamento do septo interfolicular com congestão dos vasos sanguíneos septais. Paratireóide. Grupos de pacotes densos de células principais exibiam atrofia, mudanças degenerativas e necróticas; moderado a marcado espessamento do tecido conectivo da margem foi visto entre grupos de células principais. Testículos. Redução no número de túbulos seminíferos, apresentavam-se dilatados e separados; redução no número de espermatogônias; túbulos seminíferos também exibiram vários graus de degeneração, necrose e atrofia com massa degenerada na luz. Ovários. Redução no número de folículos primários. Cérebro. Vários graus de congestão e edema cerebral; leve edema perineural e perivascular, congestão e degeneração neural; as mudanças degenerativas precoces foram associadas com satelitose e neuronofagia; em caprinos do G3 degeneração das células de Purkinje no fólio cerebelar.

(E) = Intoxicação experimental, $\mathrm{G}=$ Grupo, $3 / 5=3$ dos 5 animais totais do grupo, $4 / 5=4$ dos 5 animais totais do grupo, $10 / 15=10$ dos 15 animais totais do experimento.

Quadro 6. Hipervitaminose D em suínos: aspectos toxicológico, clínico e bioquímico

\begin{tabular}{|c|c|c|c|c|c|c|}
\hline Referências & $\begin{array}{l}\text { Idade dos } \\
\text { animais }\end{array}$ & $\begin{array}{c}\text { Forma de } \\
\text { Vitamina D }\end{array}$ & $\begin{array}{l}\text { Dose, período e via } \\
\text { de administração }\end{array}$ & Evolução e desfecho & Quadro clínico & Alterações bioquímicas \\
\hline Long $1984(\mathrm{~N})$ & Adultos & Vit. $\mathrm{D}_{3}$ & Vit. $\mathrm{D}_{3}$ VO 2 dias & $\begin{array}{l}\text { No segundo dia após a into- } \\
\text { xicação, três animais morre- } \\
\text { ram. Cinco porcos morre ram } \\
\text { após } 2 \text { semanas }\end{array}$ & $\begin{array}{l}\text { Dois dias após a ingestão } \\
\text { da comida, apresentaram } \\
\text { letargia e vômito }\end{array}$ & $\begin{array}{l}\text { Hipercalcemia entre o tercei- } \\
\text { ro e nono dias. Hiperfosfate- } \\
\text { mia e hipermagnesemia entre } \\
\text { o primeiro e segundo dias }\end{array}$ \\
\hline $\begin{array}{l}\text { Haschek et al. } \\
1978 \text { (E) }\end{array}$ & 3-4 meses & Vit. $\mathrm{D}_{3}$ & $\begin{array}{l}1320 \mathrm{IU} / \mathrm{kg} \text { (grupo con- } \\
\text { trole VO) 825,000IU/ } \\
\text { kg (grupo teste VO) }\end{array}$ & $\begin{array}{l}\text { Eutanasiados nos dias } 1,2,3 \text {, } \\
4,7 \text { e } 14\end{array}$ & $\begin{array}{l}\text { No grupo teste houve per- } \\
\text { da de peso, anorexia, fra- } \\
\text { queza e diapnéia }\end{array}$ & $\begin{array}{l}\text { Hipercalcemia } 12 \text { horas após } \\
\text { a intoxicação }\end{array}$ \\
\hline
\end{tabular}

$\overline{(\mathrm{N})}$ = Intoxicação experimental, G = Grupo, VO = Via oral.

Quadro 7. Hipervitaminose D em suínos: aspectos macroscópico e microscópico

\begin{tabular}{lll}
\hline \multicolumn{1}{c|}{ Referências } & Macroscopia & \multicolumn{1}{c}{ Microscopia óptica } \\
\hline Long 1984 (N) & $\begin{array}{l}\text { Gastrite hemorrágica e difusa pneumonia inters- } \\
\text { ticial em todos os animais. Degeneração miocár- } \\
\text { dica e nefrose foram observadas em cinco porcos }\end{array}$ & $\begin{array}{l}\text { Necrose e mineralização na mucosa gástrica, rins, e íntima dos pequenos va- } \\
\text { sos do coração e pulmões }\end{array}$ \\
Haschek et al.1978 (E) & $\begin{array}{c}\text { Osso. Alterações regressivas nos condrócitos, osteoblastose osteócitos se ini- } \\
\text { ciaram um dia após receber vitamina } \mathrm{D}_{3} \text { e resultaram em osteonecrose com } \\
\text { subsequente osteoclasia e osteopenia }\end{array}$
\end{tabular}


Quadro 8. Hipervitaminose D em cães: aspecto toxicológico, clínico e laboratorial

\begin{tabular}{|c|c|c|c|c|c|c|}
\hline Referências & Animais & Forma de vit. D & $\begin{array}{c}\text { Dose e via } \\
\text { de adm. }\end{array}$ & $\begin{array}{l}\text { Evolução e } \\
\text { desfecho }\end{array}$ & Quadro clínico & $\begin{array}{c}\text { Alterações bioquímicas } \\
\text { e urinálise }\end{array}$ \\
\hline
\end{tabular}

Spangler et al. Adultos
$1979(\mathrm{E})$
1979 (E)

\begin{tabular}{|c|c|c|c|c|}
\hline $\begin{array}{l}\text { Cumming, } \\
1991(\mathrm{~N})\end{array}$ & $\begin{array}{l}\text { Fêmea } \\
\text { (4 meses) }\end{array}$ & $\begin{array}{l}\text { Vit. D rodenti- } \\
\text { cidas }\end{array}$ & $?$ & $\begin{array}{l}\text { Morte natural } \\
\text { em 2-3 dias }\end{array}$ \\
\hline
\end{tabular}

Mellanby et al. Cão (3 anos) Cole-calciferol $2006(\mathrm{~N})$
500 ou $1000 \mathrm{mg} /$ Morte em 8 a 49 Marcada diminuição do consumo Kg/dia/VO (6 a 21 dias. de ração após o 8o dia. Com duas dias)

em 2-3 dias

semanas, desidratação, pelo seco e quebradiço, atrofia muscular, especialmente os músculos da mastigação. Um cão, no 19o dia e outro no $21^{\circ}$ dia com severa depressão e coma. Consumo de água e produção de urina flutuou durante o experimento, mas uma gradual diminuição foi aparente Profunda letargia, polidipsia, vômitos repetidos. Evoluindo para febre $\left(40^{\circ} \mathrm{C}\right)$, gastroenterite hemorrágica, aumento do ritmo respiratório progredindo para severa dispnéia com ta-quicardia, marcado edema pulmonar e morte. Letargia, perda de peso, polidi- Hipercalcemia psia e poliúria semana
EAS: Glicose - glicosúria em 2 cães na $1^{a}$ semana do tratamento. Bioquímica: Cálcio e uréia - aumento na $1^{\mathrm{a}}$ semana. Creatinina - aumentou, mas não excedeu a normalidade. Atividade renina plasmática marcado aumento nas duas semanas e diminuição na $3^{\text {a }}$

$$
\text { - }
$$

(E) = Intoxicação experimental, $\mathrm{VO}$ = Via oral, $(\mathrm{N})$ = Intoxicação natural, ? = Dose desconhecida.

Quadro 9. Hipervitaminose D em cães: aspectos macroscópico, microscópico e ultraestrutural

\begin{tabular}{|c|c|}
\hline Referências & Macroscopia \\
\hline Spangler et al. 1979 (E) & $\begin{array}{l}\text { Sistema cardiovascular. Placas verme- } \\
\text { lhas elevadas e ásperas de tamanhos va- } \\
\text { riados na aorta ou artéria pulmonar, ou } \\
\text { ambos; dois cães evidenciaram focal pa- } \\
\text { lidez no músculo papilar do ventrículo } \\
\text { esquerdo. Tireóides. Aumentadas e pá- } \\
\text { lidas. Sistema digestivo. Úlceras na } \\
\text { margem rostroventral da língua. Rins. } \\
\text { Cães com menos de duas semanas de } \\
\text { tratamento com superfície cortical lisa } \\
\text { e mosqueada de vermelho e cinza; em } \\
\text { cães com mais de } 14 \text { dias de tratamen- } \\
\text { to, a superfície cortical era mosqueada } \\
\text { e marcada por uma fina textura granu- } \\
\text { lar }\end{array}$ \\
\hline
\end{tabular}

Cumming $1991(\mathrm{~N})$
Pulmão. Edema pulmonar. Fígado. Congestão hepática decorrente de insuficiência cardíaca aguda. Coração. Miocárdio com áreas esbranquiçadas

Microscopia óptica e eletrônica

Microscopia Óptica: Sistema cardiovascular. As placas vermelhas descritas nas artérias foram caracterizadas por proliferação intimal, edema subintimal, depósitos de hemossiderina com fina mineralização granular e separação edematosa das fibras colágenas e elásticas subjacentes; os focos pálidos no músculo papilar do ventrículo esquerdo correspondiam à degeneração miocardial; degeneração intimal e mineralização das artérias coronarianas intramurais. Pulmão. Mineralização das vias aéreas terminais. Tireóide. Hipertrofia e hiperplasia das células parafoliculares (células “C"). Sistema digestivo. Glossite ulcerativa; extensa degeneração e deposição mineral na mucosa gástrica. Rins - cães com menos de duas semanas de tratamento com degeneração segmentar de células epiteliais (atrofia de células epiteliais com aumento do diâmetro luminal); os poucos depósitos de Ca eram aleatoriamente distribuídos; áreas de parênquima renal entremeadas com segmentos de degenera ção tubular; cães com mais de 14 dias de tratamento com áreas extensas de degeneração tubular, colapso e esclerose intersticial segmentar radial; todos os cães tinham leve degeneração glomerular caracterizada por dissolução ocasional de tufo glomerular; proteína dentro do espaço urinário do glomérulo afetado; colapso glomerular frequentemente era associado com marcada hiperplasia do aparelho justaglomerular; todos os cães com alterações tubulares mostraram discreto acúmulo focal de células mononucleares nestas áreas associadas com túbulos rompidos; a extensão e distribuição da deposição mineral variaram grandemente, mas eram mais severas nos cães tratados por períodos maiores; a distribuição era aparentemente ao acaso com respeito à porção do néfron afetado; depósitos minerais multifocais na cortical eram comuns; um cão mostrou mineralização predominante na junção córtico-medular; mineralização medular era restrita principalmente às concreções intratubulares; proeminência do aparelho justaglomerular era atribuída principalmente ao aumento do tamanho e número de células localizadas no ângulo formado por arteríolas aferente e eferente; celularidade era significativamente maior no córtex renal

Microscopia Eletrônica. Rins. Numerosos grânulos citoplasmáticos secretores (0,3 a $0,7 \mathrm{~nm}$ de diâmetro) eram notados nas células justaglomerulares dos cães tratados; estas células não eram vistas no aparelho justaglomerular dos cães controles

Microscopia Óptica. Coração. As áreas brancas do miocárdio correspondiam à ne crose aguda multifocal com degeneração de células do miocárdio e extensa deposição de Ca. Fígado. Congestão centrolobular decorrente da falência cardíaca. Estômago. Marcada necrose e calcificação em áreas profundas das glândulas gástricas

(E) = Intoxicação experimental, (N) = Intoxicação natural. 
Quadro 10. Hipervitaminose D em gatos: aspectos toxicológico, clínico e laboratorial

\begin{tabular}{|c|c|c|c|c|c|c|}
\hline Referências & Animais & $\begin{array}{c}\text { Forma de } \\
\text { vitamina D }\end{array}$ & $\begin{array}{l}\text { Dose e via } \\
\text { de adm. }\end{array}$ & Evolução e desfecho & Quadro clínico & Alterações bioquímicas e EAS \\
\hline $\begin{array}{l}\text { Thomas et al. } \\
1990(\mathrm{~N})\end{array}$ & $\begin{array}{l}\text { Gato } \\
\text { (6 meses) }\end{array}$ & $\begin{array}{l}\text { Colecalciferol } \\
\text { (rodenticida) }\end{array}$ & $50 \mathrm{~g} / \mathrm{VO}$ & $\begin{array}{l}\text { Eutanasiado após trata- } \\
\text { mento com dexametaso- } \\
\text { na e furosemida }\end{array}$ & $\begin{array}{l}\text { Anorexia, desidratação, dis- } \\
\text { fagia, vômito, sialorréia, po- } \\
\text { lidipsia, fraqueza muscular } \\
\text { e halitose }\end{array}$ & $\begin{array}{l}\text { Elevação nos níveis de uréia ( } 25 \\
\mathrm{mmol} / \mathrm{l}), \mathrm{creatinina}(405 \mathrm{mmol} / \mathrm{l}) \\
\text { e cálcio }(7,0 \mathrm{mmol} / \mathrm{l})\end{array}$ \\
\hline $\begin{array}{l}\text { Peterson et al. } \\
1991(\mathrm{~N})\end{array}$ & $\begin{array}{l}\text { Fêmea } \\
\text { (4 meses) }\end{array}$ & $\begin{array}{l}\text { Vit. D3 - } \\
\text { rodenticidas }\end{array}$ & ? & $\begin{array}{l}\text { Morte em 3-4 dias após } \\
\text { ingestão do veneno }\end{array}$ & $\begin{array}{l}\text { Vômitos persistentes e fra- } \\
\text { queza progressiva, evoluindo } \\
\text { para hipotermia, taquipnéia, } \\
\text { depressão, parada cárdio- } \\
\text { respiratória }\end{array}$ & $\begin{array}{l}\text { Bioquímica. Hipercalcemia, hi- } \\
\text { percalemia, hiperfosfatemia, aci- } \\
\text { dose metabólica, aumento da } \\
\text { creatinina. } \\
\text { EAS. Densidade 1032, poucos } \\
\text { cristais de oxalato de Ca }\end{array}$ \\
\hline $\begin{array}{l}\text { Morita et al. } \\
1995(\mathrm{~N}) \\
\text { (E) }\end{array}$ & $\begin{array}{l}5 \text { gatos } \\
(1 \text { a } 9 \text { anos) } \\
30 \text { gatos } \\
\text { (2 a } 3 \text { me- } \\
\text { ses) }\end{array}$ & $\begin{array}{l}1,25 \text { vit. D nara- } \\
\text { ção comercial } \\
\text { vitamina } D_{3}\end{array}$ & $\begin{array}{l}6,370 \mathrm{IU} / 100 \mathrm{~g} \\
\text { VO } \\
15,000 \mathrm{IU} / \mathrm{kg} \\
\text { para } 10 \mathrm{ani}- \\
\text { mais }\end{array}$ & $\begin{array}{l}\text { Todos morreram } \\
8 \text { morreram após 3-31 } \\
\text { dias e os demais euta- } \\
\text { nasiados }\end{array}$ & $\begin{array}{l}\text { Perda de peso, anorexia, vô- } \\
\text { mito e dispneia } \\
\text { Perda de peso, desidratação, } \\
\text { anorexia, vômito, polidipsia } \\
\text { e dispneia }\end{array}$ & $\begin{array}{l}\text { Bioquímica. Hiperfosfatemia, au- } \\
\text { mento da creatinina e uréia } \\
\text { Bioquímica. Hipercalcemia, au- } \\
\text { mento da uréia. }\end{array}$ \\
\hline
\end{tabular}

$\overline{(N)}$ = Intoxicação natural, ? = Dose desconhecida, $\mathrm{VO}$ = via oral.

Quadro 11. Hipervitaminose D em gatos: aspectos macroscópico e microscópico

\begin{tabular}{|c|c|c|}
\hline Referências & Macroscopia & Microscopia óptica \\
\hline Thomas et al. $1990(\mathrm{~N})$ & $\begin{array}{l}\text { Pulmões, fígado e baço. Con- } \\
\text { gestos. Rins. Tumefeitos com } \\
\text { estrias esbranquiçadas no cór- } \\
\text { tex. Estômago e intestino del- } \\
\text { gado. Áreas pálidas sob a se- } \\
\text { rosa. Coração. Palidez na su- } \\
\text { perfície de corte do miocárdio }\end{array}$ & $\begin{array}{l}\text { Rins. Mineralização da membrana basal dos túbulos. Pulmões. } \\
\text { Edema, mineralização da membrana basal da parede alveolar } \\
\text { com necrose focal de pneumócitos tipo I e proliferação de } \\
\text { pneumócitos tipo II. Estômago e intestino delgado. Mine- } \\
\text { ralização da mucosa e submucosa. Coração. Necrose multi- } \\
\text { focal com mineralização. Baço. Área de infarto }\end{array}$ \\
\hline Peterson et al. 1991 (N) & $\begin{array}{l}\text { Pulmões.Firmes, mosqueados, } \\
\text { avermelhados, superfície irre- } \\
\text { gular com múltiplos focos de } \\
\text { mineralização com diâmetro } \\
\text { de } 1 \text { a } 3 \text { mm }\end{array}$ & $\begin{array}{l}\text { Pulmão. Fibrina intra-alveolar, neutrófilos, macrófagos, eri- } \\
\text { trócitos e células degeneradas; infiltrado intersticial de lin- } \\
\text { fócitos. Aorta ascendente. Áreas irregulares de minerali- } \\
\text { zação, moderada infiltração por neutrófilos, macrófagos, e- } \\
\text { ritrócitos dispersos e células degeneradas. Rins. Calcifica- } \\
\text { ção multifocal na cápsula de Bowman, na parede intimal de } \\
\text { pequenos vasos sanguíneos e na membrana basal de mui- } \\
\text { tos túbulos; túbulos da junção córtico-medular com necro- } \\
\text { se aguda no epitélio e descamação de células dentro do lú- } \\
\text { men. Timo. Tecido tímico extra-torácico adjacente às glân- } \\
\text { dulas tireóides não afetadas, com densa mineralização das } \\
\text { paredes de vasos associada com moderada necrose linfóide } \\
\text { multifocal. Fígado. Necrose em hepatócitos dispersos }\end{array}$ \\
\hline
\end{tabular}

Morita et al. 1995 (N) (N) Rins e pulmões. Firmes e crepitantes ao corte. Aorta e coronárias. Parede moderadamente espessada, com superfície rugosa. Estômago. Ulceração na mucosa

(E) Rins. Mineralização na região corticomedular
(N) Aorta. Marcada mineralização na parede. Pulmões. Fibrose intersticial e múltiplos focos de mineralização na parede dos alvéolos, brônquios e bronquíolos. Na luz dos alvéolos havia numerosos macrófagos e linfócitos. Rins. Mineralização da membrana basal dos túbulos renais e cápsula de Bowman. Estômago. Mineralização da mucosa, submucosa e muscular. Osso. Marcada mineralização do tecido ósseo pericanalicular e retardamento da absorção osteoclástica

(E) Pulmões. Fibrose intersticial e múltiplos focos de mineralização na parede dos alvéolos, brônquios e bronquíolos. Na luz dos alvéolos havia numerosos macrófagos e linfócitos. Rins. Mineralização da membrana basal dos túbulos renais e cápsula de Bowman. Estômago. Mineralização da mucosa, submucosa e muscular
(N) Aumento da densidade dos pulmões, traquéia, aorta, estômago e ossos (vértebras)

$\overline{(N)}$ = Intoxicação natural.

exemplo, em geral não apresentam mineralização quando intoxicados por vitamina D, provavelmente por falta de VDRs (Barros 2011b). Também sabe-se que nem todas as células musculares lisas da aorta de coelhos adultos e ratos possuem esses receptores, o que poderia explicar a irregularidade nas calcificações arteriais. 0 mesmo autor ainda alerta para um outro tipo de mineralização que ocorre em tecidos moles, sem qualquer modificação tecidual ou sinal de alteração regressiva; nesse tipo de fenômeno, denominado de mineralização endocelular, há deposição de cálcio livre no citosol de células gigantes, macrófagos e no interior de cisternas do sarcoplasma de miócitos cardíacos (Barros 2011). Por outro lado, em animais intoxicados por plantas calcinogênicas também há evidências de modificação teci- 
dual nas artérias antes de ocorrer a mineralização. Done et al. (1976) sugerem uma sequência de alterações no desenvolvimento da mineralização tecidual na intoxicação por $S$. malacoxylon: as lesões iniciais apareceriam nas fibras elásticas das artérias, que se tornam tumefeitas, fragmentadas e depois calcificam. Em casos mais severos, uma matriz homogênea de material eosinofílico se acumula na parede alveolar e entre as fibras elásticas do endocárdio e da aorta. A matriz então calcifica, formando placas. Com doses ainda mais elevadas se observa, no pulmão, um tecido mesenquimal pouco diferenciado com a presença de células fibroblásticas que lembram tecido embrionário, às vezes com metaplasia óssea (Done et al. 1976). Com base nessas observações, não seria adequado classificar a mineralização observada nesses casos como metastática e sim como distrófica (Done et al 1976, Tokarnia et al. 2000).

Atualmente sabe-se que a mineralização observada nas intoxicações por vitamina $D$ e pelas plantas calcinogênicas é um processo ativo associado a fatores do crescimento, proteínas da matriz e outras proteínas relacionadas ao osso. A diferenciação das células musculares lisas da parede arterial induz a síntese de proteínas da matriz e, dessa forma, influenciam a mineralização das artérias (Barros et al. 2006). 0 metabólito ativo da vitamina $\mathrm{D}\left(1,25(\mathrm{OH})_{2} \mathrm{D}_{3}\right)$ media estes efeitos, ao se ligar a receptores nucleares específicos (VDR) e alterar a transcrição gênica, determinando formação de proteínas com uma sequência diferente de aminoácidos. Em outras palavras, as células musculares lisas das artérias ou de outros tecidos mesenquimais deixam de produzir actina/miosina e passam a produzir proteínas semelhantes às do tecido ósseo ou, mesmo, matriz osteóide propriamente dita, sobre as quais, mais tarde, vem a ocorrer a mineralização. Estes receptores também estão presentes em especial nos monócitos e macrófagos. De fato, as proteínas ósseas osteocalcina, osteonectina e osteopontina foram detectadas no citoplasma de macrófagos, células mesenquimais ativadas e na matriz extracelular de brônquios de coelhos intoxicados experimentalmente por $S$. malacoxylon (Barros \& Gimeno 2000, Barros et al. 2006).

\section{Osteólise osteocítica versus osteólise osteoclástica}

Um ponto, de certa forma, ainda obscuro no metabolismo e, sobretudo, no "turnover" ósseo diz respeito ao papel desempenhado por osteoclastos e osteócitos. Em 1970, Krook et al. desenvolveram a teoria, considerada controversa e por muitos como incorreta (Qing \& Bonewald 2009), denominada "bone flow - osteocytic osteolysis", que contestava o modelo até então conhecido como clássico para a formação e remodelação ósseas. A partir de então, formaram-se duas correntes de pensamento: as do que creem que o "turnover" ósseo, pelo lado reabsortivo, deve-se, principalmente, senão exclusivamente, à capacidade fagocítica dos osteoclastos, e a daqueles que atribuem esse fenômeno à ação dos osteócitos inclusos no tecido ósseo, a chamada osteólise osteocítica.

De acordo com a ideia de Krook, não haveria quantidade suficiente de osteoclastos para participar do "turnover" ósseo normal ou da perda óssea, de forma que a reabsorção ocorreria a partir das lacunas (dentro do osso) pelos osteócitos e não pelos osteoclastos, na superfície das trabéculas. Já os pesquisadores que defendem a teoria da osteólise osteoclástica, acreditam que o papel primordial dos osteoclastos na reabsorção óssea está bem elucidado.

Já em 1977, Parfitt contestou e considerou inválidos os argumentos de Krook et al. (1970); em sua opinião, a ampliação das lacunas são apenas artefatos de técnica resultantes do processamento do material. Lacunas semelhantes também são encontradas no entorno de osteócitos mais jovens; por outro lado essa ampliação das lacunas poderia ser consequência da falta de mineralização na matriz periosteocítica pela incorporação do osteócito osteóide. A seguir, diversos trabalhos foram publicados contestando ou apoiando ambas as teorias.

Embora a maioria dos pesquisadores considere a teoria da "osteólise osteocítica" como controversa ou incorreta, entendemos que essa discussão deve ser feita, conjuntamente, por profissionais das mais diversas áreas envolvidas, como patologistas, fisiologistas, endocrinologistas e biólogos que sejam especialistas em tecido ósseo.

Quadro 12. Hipervitaminose D em ratos: aspectos toxicológico, clínico e bioquímico

\begin{tabular}{|c|c|c|c|c|c|c|}
\hline Referências & Animais & Forma vit. D & $\begin{array}{c}\text { Dose e via de } \\
\text { administração }\end{array}$ & Evolução e desfecho & Quadro clínico & Alterações bioquímicas \\
\hline $\begin{array}{l}\text { Okawa et al. } \\
1980 \text { (E) }\end{array}$ & $\begin{array}{l}\text { Machos a- } \\
\text { dultos }\end{array}$ & Vit. $D_{2}$ & $\begin{array}{l}8 \mathrm{mg} / \mathrm{kg} / \mathrm{VO} / 2 \\
\text { doses (dias } 1 \mathrm{e} \\
\text { 4). }\end{array}$ & $\begin{array}{l}27 \%(13 / 48) \text { morreram } \\
\text { entre os dias } 5 \text { e } 7 ; \text { res- } \\
\text { tante foi sacrificado ao } \\
\text { longo do experimento } \\
\text { (11 dias) }\end{array}$ & $\begin{array}{l}\text { Perda de peso a partir do } 3^{\circ} \\
\text { dia e pico no } 8^{\circ} \text { e } 9 \text { o dia. Em } \\
\text { paralelo, hiporexia e em acia- } \\
\text { ção }\end{array}$ & - \\
\hline $\begin{array}{l}\text { Buffenstein et } \\
\text { al. } 1995 \text { (E) }\end{array}$ & Adultos & Vit. $D_{3}$ & $\begin{array}{l}\text { 10mg/animal/ } \\
\text { Vo/1 dose. }\end{array}$ & $\begin{array}{l}\text { Seis animais sacrifica- } \\
\text { dos5 dias após adminis- } \\
\text { tração. Um foi monitora- } \\
\text { do por } 8 \text { semanas }\end{array}$ & $\begin{array}{l}\text { Hiporexia, perda de peso, le- } \\
\text { targia dentro de } 3 \text { dias. } 0 \text { ani- } \\
\text { mal que não foi sacrificado, } \\
\text { duas semanas após a admi- } \\
\text { nistração, apresentou pele } \\
\text { ressecada e dura }\end{array}$ & $\begin{array}{l}\text { Plasma com hipercalcemia, } 25 \\
(\mathrm{OH}) \mathrm{D} \text { e } 1,25(\mathrm{OH}) 2 \mathrm{D} \text {. Dente com } \\
\text { aumento de Ca, volume, massa e } \\
\text { densidade. Fêmur com aumento } \\
\text { de volume, massa, densidade. Os- } \\
\text { so com aumento de Ca. Duodeno } \\
\text { e ceco com aumento de Ca }\end{array}$ \\
\hline $\begin{array}{c}\text { Chavhan et al. } \\
2011\end{array}$ & $\begin{array}{l}\text { Machos a- } \\
\text { dultos }\end{array}$ & Vit. $\mathrm{D}_{3}$ & $2 \mathrm{mg} / \mathrm{kg} / \mathrm{VO}$ & $\begin{array}{l}\text { Todos morreram entre } \\
\text { o } 10^{\circ} \text { e o } 19^{\circ} \text { dias após } \\
\text { a intoxicação }\end{array}$ & $\begin{array}{l}\text { Anorexia, perda de peso, rigi- } \\
\text { dez dos membros, hipotermia, } \\
\text { desidratação, dificuldade res- } \\
\text { piratória, diarreia, epistaxe e } \\
\text { convulsão }\end{array}$ & $\begin{array}{l}\text { Hipercalcemia, hiperfosfatemia, } \\
\text { aumento nos níveis de uréia e hi- } \\
\text { poproteinemia }\end{array}$ \\
\hline
\end{tabular}

$\overline{\mathrm{IN}}=$ Intoxicação natural, $(\mathrm{E})$ = Intoxicação experimental, VO = Via oral, 13/48 - 13 dos 48 animais totais do experimento. 
Quadro 13. Hipervitaminose D em ratos: aspectos macroscópico, microscópico, ultraestrutural e radiográfico

\begin{tabular}{|c|c|}
\hline Referências & Macroscopia \\
\hline $\begin{array}{c}\text { Okawa et al. } \\
1980(\mathrm{E})\end{array}$ & $\begin{array}{l}\text { Coração. Áreas brancas linea- } \\
\text { res e pontilhadas, de exten- } \\
\text { sa calcificação no subepicár- } \\
\text { dio ao longo das artérias co- } \\
\text { ronarianas; músculos car- } \\
\text { díacos enfraquecidos. Rins. } \\
\text { Amolecidos e com superfície } \\
\text { granular. Estômago. Animais } \\
\text { mais afetados, esporadica- } \\
\text { mente apresentavam áreas } \\
\text { pontilhadas calcificadas na } \\
\text { subserosa }\end{array}$ \\
\hline
\end{tabular}

Buffenstein

etal. $1995(\mathrm{E})$

Chavhan et al. Severa emaciação e focos de 2011 (E) mineralização no epicárdio, córtex renal, na serosa do estômago e intestino

$\overline{(E) ~=~ I n t o x i c a c ̧ a ̃ o ~ e x p e r i m e n t a l . ~}$

Microscopia óptica e eletrônica de células do músculo liso e interstício; acúmulo de gotículas de gordura ao longo de membranas elásticas internas e na camada central da média; desorganização de membranas elásticas e células do músculo liso. Nos animais mortos no 11ํo dia, tumefação e descamação de células endoteliais; acúmulo de células mononucleares na íntima edematosa e na média calcificada e degenerada. Coração. Áreas finamente granulares calcificadas na membrana elástica interna de artérias coronarianas $\left(2^{\circ}\right.$ e $3^{\circ}$ dias); calcificação por quase toda a parede vascular no 4o e 5o dias. Leve acúmulo de gotículas de gordura nestas áreas calcificadas. Necrose de células do músculo cardíaco, deposição de cálcio, infiltrado neutrofílico e proliferação de células mesenquimais foram ocasionalmente observados ao redor dos vasos sangüíneos afetados. Animais mortos no $11^{\circ}$ dia, marcado edema na íntima das arteríolas. Necrose hialina amorfa era comum em ramos médios da artéria coronária. No ramo principal da coronária, edema intimal e medial, necrose medial, tumefação de células endoteliais, proliferação de células mononucleares (PAS e Alcian blue positivo). Calcificação mais observada em áreas de fragmentação da membrana elástica interna. Rins. 3o dia, calcificação da membrana elástica interna na artéria renal e artérias interlobulares. $4^{\circ}$ dia, tumefação e vacuolização de células endoteliais, aparecimento de células gigantes multinucleadas na superfície intimal, células mononucleares na íntima e média da artéria renal. Calcificação nas células epiteliais dos túbulos contorcidos distais no $2^{\circ}$ dia. No $4^{\circ}$ dia, degeneração e necrose dos túbulos uriníferos. No 4o e 5ํ dias, depósitos de cálcio na membrana basal das cápsulas de Bowman, glomérulos, túbulos proximais, assim como nas células da lâmina parietal da cápsula de Bowman. Por vezes, havia calcificação acompanhada com espessamento da membrana basal da cápsula de Bowman, necrose e destruição do glomérulo. No $11^{\circ}$ dia, calcificação em outros elementos teciduais e regeneração de células epiteliais eram vistas ocasionalmente em muitos túbulos uriníferos. Sistema digestivo. $5^{\circ}$ dia, extensa calcificação na média das artérias mesentéricas; edema e necrose de parede em artérias do trato gastrintestinal; degeneração e necrose em células epiteliais do estômago; extensa calcificação, junto com alterações vasculares na mucosa gástrica e túnica muscular gástrica e intestinal. No $11^{\circ}$ dia, as alterações eram mais características que nos animais sacrificados em outros dias. Acúmulos de células mononucleares, misturados com raras células gigantes eram evidentes nas lesões da túnica muscular do estômago e intestino em adição com a calcificação. Em artérias mesentéricas, aumento de volume de células endoteliais e acúmulo de células mononucleares ao redor das células da íntima. Pulmão - marcado edema, discreta calcificação dos septos alveolares, aumento de volume de células epiteliais alveolares e pequena agregação de células mononucleares vistas nos septos de ratos sacrificados no 5 o dia. Discreta calcificação foi ocasionalmente vista na parede de pequenas artérias, no interstício ao redor de artérias e brônquios e na membrana elástica de artérias.

Microscopia eletrônica. Aorta. Edema no espaço subendotelial e média; desorganização e necrose medial; extensa calcificação da média

Presença de depósitos de cálcio nas áreas cutâneas mais afetadas.

Microscopia óptica: Língua. Mineralização na parede dos vasos sanguíneos. Estômago. Mineralização na mucosa, muscular da mucosa, muscular externa e parede de vasos sanguíneos. Intestinos delgado e grosso. Mineralização da camada muscular externa. Rins. Calcificação principalmente nas regiões cortical e medular. Nos túbulos havia mineralização e necrose coagulativa. Observaram-se ainda mineralização na membrana basal dos túbulos, na parede dos vasos sanguíneos e na cápsula glomerular. Laringe e traquéia. Mineralização na lâmina própria da laringe, na cartilagem e na membrana basal da mucosa do epitélio da traquéia. Havia ainda, na mucosa traqueal, infiltrado inflamatório com células epiteliais descamadas. Pulmões. Mineralização na mucosa brônquica, nos alvéolos e septos interalveolares. Observaram-se também infiltrado inflamatório constituído por macrófagos, linfócitos e, ocasionalmente, neutrófilos e células gigantes entre os alvéolos. Outros achados incluíram enfisema, hemorragia e edema. Coração. Mineralização no epicárdio, miocárdio, endocárdio, válvulas cardíacas e coronárias. Havia ainda degeneração de miofibras, proliferação de tecido conjuntivo e infiltrado inflamatório mononuclear. Aorta. Mineralização entre as fibras elásticas da túnica média. Baço. Calcificação das artérias centrais dos nódulos linfáticos e da superfície capsular. Fígado. Vacuolização (degeneração gordurosa) dos hepatócitos. Adrenal. Marcada congestão da medular. Cérebro. Mineralização das artérias do plexo coróide, neuronofagia e satelitose no córtex 
Quadro 14. Intoxicação por plantas calcinogênicas: aspectos toxicológico e clínico

\begin{tabular}{|c|c|c|c|c|c|}
\hline Referências & Animais & Planta & Dose e via de administração & Evolução e desfecho & Quadro clínico \\
\hline $\begin{array}{l}\text { Döbereiner } \\
\text { et al. } 1971 \\
(\mathrm{~N} / \mathrm{E})\end{array}$ & Bovinos & $\begin{array}{l}\text { Solanum mala- } \\
\text { coxylon }\end{array}$ & $\begin{array}{l}\text { (E) } 0,16 \text { a } 1,0 \mathrm{~g} / \mathrm{kg} / \mathrm{semana} / \\
\text { VO (folhas secadas ao ar livre) } \\
\text { Dose total: } 2,86-9,01 \mathrm{~g} / \mathrm{kg} / \mathrm{VO} \\
\text { (folhas secadas ao ar livre) }\end{array}$ & $\begin{array}{l}\text { (E) Morte espontânea ou sa crifício: } \\
4 \text { semanas e } 2 \text { dias a } 1 \text { ano e duas } \\
\text { semanas }\end{array}$ & $\begin{array}{l}\text { (N) Emagrecimento, andar rígido, apoio } \\
\text { sobre membros anteriores, carpo com le- } \\
\text { ve flexão, cascos posteriores crescidos } \\
\text { So pro aórtico } \\
\text { (E) Emagrecimento, andar rígido, cifose, } \\
\text { sopro cardíaco, arritmia cardíaca, car- }\end{array}$ \\
\hline
\end{tabular}

Barros et al. Coelhos S. malacoxylon

1981 (E)

\begin{tabular}{|c|c|c|}
\hline $\begin{array}{l}\text { Riet-Correa. } \\
\text { et al } 1981 \text { (E) }\end{array}$ & Coelhos & N. veitchii \\
\hline $\begin{array}{l}\text { Barros } 1989 \\
\text { (E) }\end{array}$ & Coelhos & $\begin{array}{l}\text { N. veitchii e } \\
\text { S. malacoxylon }\end{array}$ \\
\hline $\begin{array}{c}\text { Barros et al. } \\
1992(\mathrm{~N})\end{array}$ & Ovinos & N. veitchii \\
\hline $\begin{array}{l}\text { Moraña et al. } \\
1994 \text { (E) }\end{array}$ & Coelhos & S. malacoxylon \\
\hline $\begin{array}{c}\text { Barros et al. } \\
1996(\mathrm{E})\end{array}$ & Coelhos & S. malacoxylon \\
\hline $\begin{array}{c}\text { Barros \& Rosa } \\
1999 \text { (E) }\end{array}$ & Coelhos & S. malacoxylon \\
\hline $\begin{array}{l}\text { Mello et al. } \\
1999 \text { (E) }\end{array}$ & Ratos & $\begin{array}{l}\text { S. malacoxylon } \\
\text { e N.veitchii }\end{array}$ \\
\hline
\end{tabular}

Gomar et al. 2000 (E)

Coelhos e Ovinos

S. malacoxylon 2005 (E)

Rissi et al. Ovinos N. veitchii $2007(\mathrm{~N})$

Santos et al. Búfalos $2011(\mathrm{~N})$
$2 \mathrm{ml}$ extrato/kg/VO (extrato: G1, G2, G3, G4, G5 e G6 sacrificados $20 \mathrm{~g} / 400 \mathrm{ml}$ água destilada). 6, 12, 24, 48, 72 e 96 horas após, res G1, G2 e G3 (uma dose); G4 pectivamente (duas doses); G5 (três doses); G6 (4 doses) Folhas secas, moídas e misturadas à ração ad libitum (10 e $50 \%)$

Ingestão crônica de pastagem infestada

Morte espontânea ou sacrifício 17 Emagrecimento, insuficiência valvular meses após o diagnóstico

$100 \mathrm{mg}$ de folhas dessecadas Morte espontânea ou sacrifício em (extrato aquoso) $/ \mathrm{kg} / \mathrm{dia} / \mathrm{VO}$ até 14 dias ou IV

$100 \mathrm{mg}$ de folhas dessecadas Sacrificados após 96 horas (extrato aquoso) $/ \mathrm{kg} / \mathrm{dia} / \mathrm{VO}$

$100 \mathrm{mg}$ de folhas dessecadas Sacrificados no $4^{\circ}$ dia (extrato aquoso) $/ \mathrm{kg} / \mathrm{dia} / \mathrm{VO}$

(3 dias)

Protocolo I: Administração an- -

tesdo acasalamento. G1 solução fisiológica (15 fêmeas e 5 machos). G2 $3 \mathrm{mg} / \mathrm{kg} /$ dia de vitamina $\mathrm{D}_{3}$ (3 machos e 9 fêmeas), G3 $10,9 \mathrm{~g} / \mathrm{kg} /$ dia (extrato aquoso) de Solanum malacoxylon (3 machos e 9 fêmeas), G4 10,9g/ $\mathrm{kg} /$ dia (extrato aquoso) de $\mathrm{Nie}$ rembergia veitchii (1 macho e 4 fêmeas). Protocolo II: Ratas prenhes. G5 e G6 5,4,10,9 e 21,7g/ $\mathrm{kg} /$ dia de S. malacoxylon e N. veivamente. G7 0,75, 2,25 e 3,75 $\mathrm{mg} / \mathrm{kg} /$ dia de vitamina $\mathrm{D}_{3}$ esquerda e sopro, carótidas rugosas, pulso das artérias superficiais pouco perceptíveis

Anorexia, depressão e diarreia e constipação

(1)

Protocolo I: G2 e G3. Emagrecimento progressivo, pêlo arrepiado, andar relutante, respiração dificultada e arqueamento da coluna e de ossos longos. Vinte dias após acasalamento observaramse: G1. Elevado percentual de fêmeas gestantes; G2,G3 e G4. Só 1 animal gestante em cada grupo. Protocolo II: G5 e G7. Redução da taxa de parto e de natalidade nas doses mais elevadas. G5. Não ocorreram partos, redução do ganho de peso das fêmeas durante a gestação, mor te de fêmeas gestantes ( $9^{\circ}$ dia da gestação), diminuição do número de ratos nascidos, redução do número de implantes uterinos (7ํ dia de gestação). G6. Sem altchii (extrato aquoso), respectiterações. G7. Redução do ganho de peso das fêmeas durante a gestação, morte de fêmeas gestantes (21음 dia da gestação), diminuição do número de ratos nascidos, aumento de reabsorção embrionária. Alterações morfológicas em $100 \%$ dos fetos na dose de $10,9 \mathrm{~g} / \mathrm{kg} /$ dia, caracterizadas por aumento de volume de articulações, arqueamento da coluna e membros curtos, arqueados e alterações faciais

4 coelhos $300 \mathrm{mg}$ de folha VO Todos os animais intoxicados mor- Anorexia, perda de peso, diarreia e rinite por 9 dias e dieta com $0,87 \%$ e reram $0,78 \%$ de cálcio e fósforo, respectivamente. 2 coelhos (placebo por 9 dias)

De 460 ovinos, 43 foram intoxicados

29 morreram espontaneamente e

13 morreram subitamente e 30 apresentaram perda de peso, relutância em se movimentar, andar rígido, abdômen re-

S. glaucophyllum De 40 búfalos, 5 foram intoxi- 3 animais recuperaram-se e 2 fo- traído e cifose.

(=S. malacoxylon) cados ram eutanasiados to progressivo, dorso arqueado, marcha rígida, por vezes com dificuldade para se levantar e locomover, permanecendo apoiando sobre os carpos

$\overline{(E) ~=~ I n t o x i c a c ̧ a ̃ o ~ e x p e r i m e n t a l, ~}(\mathrm{~N} / \mathrm{E})=$ Intoxicações natural e experimental, $\mathrm{IM}=$ Intramuscular, $(\mathrm{N})=$ Intoxicação natural, VO = Via oral,G = Grupo. 
Quadro 15. Intoxicação por plantas calcinogênicas: aspectos radiológico, macroscópico, microscópico, ultraestrutural e imuno-histoquímico

\begin{tabular}{ccc}
\hline Referências & Macroscopia & $\begin{array}{c}\text { Radiologia, microscopia óptica, microscopia } \\
\text { eletrônica e imunohistoquímica }\end{array}$ \\
\hline
\end{tabular}

Döbereiner et al. 1971 (N) Pulmão. Enfisema pulmonar, aumento da consis$(\mathrm{N} / \mathrm{E})$

Barros et al. 1981 (E)

Riet-Correa et al. 1981 Coração e aorta. Placas calcárias na aorta torácica e (E) abdominal, mineralização das cordas tendíneas das valvas aurículo-ventriculares e valvas sigmóides esquerdas. Rim. Depósitos calcários no córtex e medula. Pulmão. Enfisema e depósitos calcários no lobos diafragmáticos
(N) Pulmão. Alvéolos dilatados e com paredes espessadas por tecido fibrilar frouxo com células mesenquimais e fibroblásticas, lembrando tecido embrionário; placas de substância homogênea eosinofílica, com características de colágeno, parcialmente calcificada com pequenas células inclusas e, às vezes, circundada por células poligonais ou alongadas (tecido osteóide e ósseo). Depósitos de cálcio (grânulos, grumos e placas) na substância intercelular. Presença de céluas gigantes do tipo corpo estranho. Endocárdio. Incrustações em fibras elásticas por sais de cálcio e deposição de cálcio sob forma de grânulos, grumos e placas no permeio de, e impregnando substância homogênea eosinofílica, com presença de células mesenquimais. Nota-se tecido cartilaginoso na região de inserção das valvas. Aorta e outras artérias. Depósitos maciços de cálcio em áreas maiores ou menores na porção interna da média, semelhante às formas encontradas no endocárdio. Fibras elásticas desaparecem nestas áreas de calcificação; em outras áreas observam-se incrustações nas fibras elásticas por sais de cálcio ou sob forma pulverulenta ou de grânulos; há áreas de afastamento das fibras pela substância homogênea eosinofílica. 0 processo de calcificação atinge a íntima sob forma de grânulos. Rim. Sobretudo na área justacortical, há depósitos de cálcio (às vezes com estrutura lamelar) nos túbulos uriníferos, em parte dilatados, com destruição do epitélio. Calcificação do epitélio tubular e da membrana basal, com depósito de cálcio no tecido intersticial. Tendões. Depósitos de cálcio nos fascículos tendinosos, com ninhos de células mesenquimais que, ás vezes, têm aspecto de condrócitos

(E) Lesões semelhantes à (N), em adição encontrou-se depósito de cálcio, sob forma de grumos e pequenas placas, na lâmina própria dos brônquios e na cartilagem peribronquial; depósito de cálcio na cápsula e trabéculas do baço; lesões semelhantes às arteriais em veias jugular e jejunal

Microscopia óptica. Aorta. (24 a 48 h: lesões iniciais) perda focal da ondulação normal da lâmina elástica em associação com um aumento da substância fundamental, especialmente no terço interno da média; algumas placas irregulares mostraram um fino depósito de Ca nas fibras elásticas. (48 a 72 h) aumento do depósito de Ca e, em algumas áreas, proliferação de macrófagos e células gigantes fagocitando o material calcificado. (72 a $96 \mathrm{~h}$ ) depósitos minerais formando grandes massas amorfas

Microscopia eletrônica. Aorta. Coelhos sacrificados 6 horas, porções de células do músculo liso mostraram citoplasma levemente alterado e um aumento na relação nuclear-citoplasmática; aumento do retículo endoplasmático rugoso, do aparelho de Golgi e do número de ribossomos livres; marcada "clasmatosi" e inconstante perda parcial da folds nuclear; fibroblastos atípicos. Em áreas mais severas, marcada alteração em cé lulas do músculo liso; lâmina basal irregular e perda parcial ou total de fibrilas e densificações intracitoplasmáticas. Fibras elásticas mostraram banda periférica elétron-densa, algumas vezes com um fino depósito cristalino

Microscopia óptica. Aorta. Degeneração, ruptura e calcificação das fibras elásticas, hiperplasia da íntima e formação de placas de calcificação, calcificando fibras elásticas, colágenas e o tecido intersticial. Coração. Lesões similares às encontradas na aorta, com acúmulo de células mononucleares ao redor das áreas calcificadas. Pulmão. Hiperplasia dos septos interalveolares, com formação de tecido conjuntivo frouxo e calcificação. Rim. Calcificação da íntima e média das artérias, espessamento e calcificação da cápsula de Bowman, calcificação nos túbulos com formação de cilíndros de cálcio, proliferação de tecido conjuntivo frouxo e depósito de sais de cálcio no interstício. Ossos. Placa epifisária e cartilagem articular mais fina e inativa; epífise e metáfise com retenção da matriz condróide, degeneração e necrose de osteócitos, com perda da basofilia das lacunas e numerosas linhas cimentadas (evidências de inibição da osteólise e condrólise osteocítica); a esponjosa primária muito estreita e trabéculas espessadas e confluentes, evidenciando um processo de osteopetrose; revestimento osteoblástico escasso e osteoblastos diminuídos de volume; algumas áreas com necrose da matriz óssea, com presença de osteoclasia; nos cortes transversais da diáfise com degeneração e necrose dos osteócitos, numerosas linhas cimentadas e áreas de necrose da matriz ós sea com osteoclasia

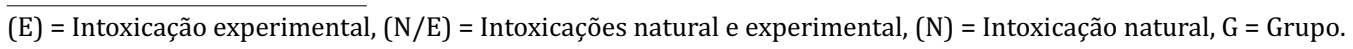


Quadro 15 (cont.). Intoxicação por plantas calcinogênicas: aspectos radiológico, macroscópico, microscópico, ultraestrutural e imuno-histoquímico

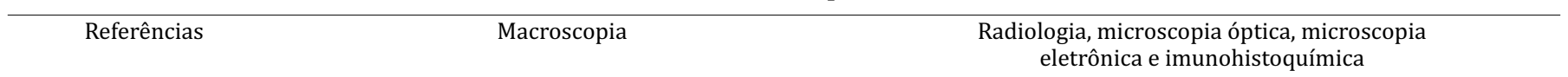

Barros 1989 (E)

Barros et al. $1992(\mathrm{~N}) \quad$ Animais que morreram apresentaram abundante es puma branca nas narinas e boca, alguns com cianose. Pulmão. Aumento da consistência e diminuição da creptação, ao corte, fluía líquido espumoso dos brônquios e traquéia. Artérias. Todas (exceto as pulmonares) com irregularidades na superfície da íntima. Rim. Estriações brancas na cortical e na medular. Rúmen e abomaso. Estriações esbranquiçadas na muscular. Coração. Valvas mitrais e sigmóides aórtica espessadas, irregulares, endurecidas e rangiam ao corte; alteração semelhante na cordoalha tendinosa. Uma ovelha também apresentou dilatação das câmaras cardíacas, hidrotórax, hidropericárdio, ascite e fígado de noz-moscada

Moraña et al. 1994 (E) Estômago. Parede espessada decorrente de edema entre mucosa e as camadas musculares, hiperemia e edema da mucosa gástrica, ocasionais áreas de necrose na mucosa fúndica, aumento na secreção mucosa, estriações esbranquiçadas nas capas musculares, visíveis através da serosa; o corte nestas áreas revelou depósitos minerais de aspecto granular, secos e de consistência dura
Microscopia eletrônica. Miócitos da parede arterial, estômago e intestino. Predomínio de células do tipo sintético sobre as do tipo contrátil, conduzindo a alterações da matriz extracelular que finalmente culminam com precipitação de fosfato de cálcio sob a forma de hidroxiapatita. Aparentemente, as deposições de Ca se iniciam nas vesículas matriciais, mas também são observadas ao longo de fibras elásticas da parede arterial e, por vezes, no colágeno. Miocárdio. Depósitos de cálcio nas cristas das mitocôndrias, eventualmente em localização interfibrilar, mas também sob a forma de agregados cristalinos de localização extracelular; estas alterações conduzem à degeneração e necrose destas células

Radiologia: Aumento da radiopacidade das carótidas

Microscopia óptica: Artérias. Mineralização subintimal da média, áreas de metaplasia óssea e cartilaginosa; proliferação da íntima nas áreas com mineralização, particularmente nas artérias do tipo muscular que, em algumas áreas, alcançava uma espessura de mais de 1/3 da média com resultante diminuição do lúmen; lâminas elásticas sem ondulação, fragmentadas e calcificadas em muitos pontos. Coração. Miocárdio com áreas de destruição das fibras cardíacas com discreta deposição de cálcio e fibrose, acompanhadas de infiltração de macrófagos, em outras áreas, acentuada fibrose com mineralização discreta ou ausente; as coronárias com mineralização da média e proliferação irregular da íntima, deposição de cálcio sob forma pulverulenta ou em placas; valvas mitral e sigmóide aórtica com acentuada calcificação e extensas áreas de metaplasia óssea e cartilaginosa, eventualmente ocorriam cavidades repletas de células adiposas, vasos sangüíneos e tecido mielóide. Rim. Mineralização das artérias e arteríolas com proliferação da íntima, fibrose intersticial, proliferação mesangial e espessamento da cápsula de Bowman, esclerose glomerular. Tireóide. Hiperplasia de células C. Pulmões. Congestão e edema. Ossos. Espessamento das trabéculas e formação de osteôneos na epífise dos ossos longos ou na porção central da costela; placa epifisária selada, com ninhos de células cartilaginosas e a esponjosa primária eram constituídas de trabéculas espessas, confluentes, com retenção de centros condróides e, por vezes, formando osteôneos; nos cortes transversais da metáfise apareciam osteôneos com lacunas osteocíticas vazias e desorganização das lamelas intersticiais

Microscopia óptica. Estômago. Marcada mineralização das camadas musculares e das paredes arteriais, edema da lâmina própria, particularmente da zona foveolar e da submucosa e hemorragias capilares na mucosa. Grande número de células multinucleadas foram observadas na mucosa, algumas com minerais no seu citoplasma

Microscopia eletrônica. Estômago. Células musculares lisas com dilatação do retículo endoplasmático, aumento do número de mitocôndrias, diminuição das vesículas pinocitóticas das miofibrilas e densificações citoplasmáticas. Na matriz extracelular, cristais de cálcio associados a fragmentos celulares recobertos por membranas de tamanhos variáveis. As células gigantes presentes na lâmina própria exibiam depósitos minerais em forma de agulhas, em alguns casos rodeados por membrana e, em outros, no interior do citoplasma como um produto endocelular. Depósitos minerais de aspectos granular sobre as cristas das mitocôndrias afetadas

Microscopia eletrônica. Ossos. Osteócitos com diversos graus de atrofia e necrose, lacunas osteocíticas com restos celulares ou vazias, mineralização do tecido osteóide perilacunar; osteoblastos com atrofia, diminuição das organelas de síntese e, por vezes, exibiam núcleos picnóticos e estavam livres dos canais de Havers; osteoclastos com borda pregueada em íntimo contato com a matriz mineralizada não erodida, região vesicular pouco desenvolvida e ausência da zona clara na periferia da borda pregueada; em alguns canais de Havers foram identificados macrófagos em processo de fusão para formarem células gigantes

Microscopia óptica. Traquéia, brônquios e bronquíolos. Intenso infiltrado de linfócitos, macrófagos, células gigantes multinucleadas, alguns poucos mastócitos e neutrófilos, às vezes, acompanhado de calcificação das fibras elásticas da lâmina própria e da membrana basal; macrófagos e células gigantes foram vistos infiltrando o epitélio; calcificação das cartilagens traqueais e brônquicas foi vista em algumas áreas

Microscopia eletrônica. Traquéia, brônquios e bronquíolos. Infiltração de macrófagos entre as células epiteliais de revestimento e sua fusão para formar células gigantes multinucleadas e depósito de cálcio junto à lâmina basal do epitélio

$\overline{(E) ~=~ I n t o x i c a c ̧ a ̃ o ~ e x p e r i m e n t a l, ~}(\mathrm{~N} / \mathrm{E})$ = Intoxicações natural e experimental, $(\mathrm{N})$ = Intoxicação natural, $\mathrm{G}=$ Grupo. 
Quadro 15 (cont.). Intoxicação por plantas calcinogênicas: aspectos radiológico, macroscópico, microscópico, ultraestrutural e imuno-histoquímico

\begin{tabular}{ccc}
\hline Referências & Macroscopia & $\begin{array}{c}\text { Radiologia, microscopia óptica, microscopia } \\
\text { eletrônica e imunohistoquímica }\end{array}$
\end{tabular}

Gomar et al. 2000 (E)

Aguirre et al. 2005 (E) Aorta, coração e rins. Placas de mineralização

Rissi et al. 2007 (N)

Santos et al. $2011(\mathrm{~N})$

Os animais apresentavam-se caquéticos e com hipotricose generalizada. Pulmões armados e com aparente enfisema em distribuição aleatória, com alguns pontos de ossificação. Nas artérias havia irregularidade da superfície da íntima, por vezes recobertas com placas brancacentas principalmente aorta, carótidas e braquiais. No coração identificou-se calcificação, espessamento e opacidade de válvulas e cordas tendíneas que estavam mais consistentes e menos flexíveis que o normal. Algumas porções dos ten dões flexores dos membros torácicos apresentavam pontos esbranquiçados acentuados na porção distal, próximo aos sesamóides
Microscopia eletrônica. Pulmão e aorta. Células mesenquimais ativadas (algumas com características de células musculares lisas com diferenciação para o tipo sintético), as quais secretam uma matriz extracelular constituída por uma mediamente elétron-densa e algumas fibras colágenas; nas mesmas áreas se observam precipitação de sais de Ca com disposição amorfa ou cristalina. Nas áreas de acúmulo de matriz extracelular, presença de alguns macrófagos e células gigantes com cristais de Ca no citoplasma; muitas membranas basais apresentavam espessamento e replicações Imunohistoquímica. Pulmão e aorta. Expressão de osteocalcina, osteonectina e osteopontina (proteínas envolvidas no processo de mineralização dos ossos) na matriz próxima às células mesenquimais ativadas e nas áreas mineralizadas. Não se constatou a presença de sulfato de condroitina

Microscopia óptica. Aumento da reabsorção óssea na superfície endosteal da zona cortical, metaplasia mesenquimal no periósteo com formação de cartilagem, placas de crescimento com padrão irregular devido à redução focal ou difusa no número de condrócitos nas zonas hipertróficas e proliferativas

Microscopia eletrônica. Alterações degenerativas primárias nos condrócitos da zona proliferativa, redução no número e tamanho dos grânulos de proteoglicanos das áreas territoriais e interterritoriais na zona hipertrófica da cartilagem da placa de crescimento. Nos animais-controle não houve alteração

Microscopia óptica. Artérias. Mineralização na túnica média, proliferação intimal e ocasional metaplasia condroide ou óssea da média. Em 7 ovinos havia mineralização dos vasos da rete mirable carotídea. Miocárdio e pulmão. Focos de calcificação e metaplasia óssea em cardiomiócitos e septos interalveolares

Microscopia óptica. Artérias. Aorta e carótida com placas basofílicas, irregulares, multifocais principalmente na túnica média. Notava-se também desorganização e fragmentação das fibras na túnica média. Em um dos búfalos próximo às áreas de mineralização havia células semelhantes a condroblastos (metaplasia cartilaginosa). Ocasionalmente havia mineralização e proliferação na túnica íntima. Nas fibras musculares cardíacas havia irregularidade, fragmentação das fibras e deposição de grânulos basofílicos (mineralização) intracitoplasmáticos. Pulmão com mineralização e deposição de material eosinofílico similar a colágeno em septos alveolares. Notou-se também mineralização em forma de placas nas cartilagens bronquiais e ocasionalmente formação de trabéculas ósseas

Achados ultrassonográficos. Em dois animais com sintomas da doença foram visibilizadas diversas calcificações focais caracterizadas por ninhos hiperecóicos nos tendões do músculo digital flexor profundo acima e abaixo dos sesamóides proximais

$\overline{(E) ~=~ I n t o x i c a c ̧ a ̃ o ~ e x p e r i m e n t a l, ~}(\mathrm{~N} / \mathrm{E})$ = Intoxicações natural e experimental, $(\mathrm{N})$ = Intoxicação natural, $\mathrm{G}=$ Grupo.

\section{CONSIDERAÇÕES FINAIS}

Os relatos das intoxicações natural e experimental por vitamina $\mathrm{D}$, em diversas espécies, demonstram a elevada toxidez desta vitamina, independentemente da via de administração e o risco à saúde que erros na sua suplementação podem representar aos animais e aos seres humanos.

Quanto à maior ou menor sensibilidade das vias de administração capazes de intoxicar animais com vitamina $D$, uma análise comparativa fica impossibilitada frente às diferenças nos relatos quanto às doses utilizadas, tempo de experimentação e, principalmente, pelo fato de diferentes compostos com atividade de vitamina D (metabólitos ativados ou não-ativados e substâncias análogas) apresentarem variados graus de toxidez e muitos trabalhos não especificam a substância utilizada.

Embora a mineralização que ocorre nos tecidos moles de animais e humanos intoxicados por vitamina D (ou por plantas que a contêm) obviamente não deva ser considerada como metastática, como trazem diversos livros-texto, ela também, de certa forma, não se enquadra totalmente no conceito de mineralização distrófica, uma vez que não se observam lesões regressivas nas células musculares das artérias ou outros tecidos que sofrem mineralização, isto é, existe em essência, uma modificação tecidual característica de metaplasia. Dessa forma, a mineralização que ocorre na hipervitaminose D poderia ser mais apropriadamente denominada de mineralização sobre ou por metaplasia, ou simplesmente mineralização metaplásica.

Há muitas lacunas sobre a interação que ocorre entre hormônios que participam das mineralizações fisiológica e patológica. As descrições são genéricas e pouco precisas, o que dificulta ainda mais a compreensão desses fenômenos. 
Agradecimentos.- Os autores gostariam não apenas de agradecer as valiosas sugestões e correções feitas pelo Prof. Severo Sales de Barros, mas também de manifestar admiração e reconhecimento pelos seus 30 anos de trabalho na área-tema desse estudo.

\section{REFERÊNCIAS}

Aloia J., Chen D.G., Yeh J.K. \& Chen H. 2010. Serum vitamin D metabolites and intestinal calcium absorption efficiency in women. Am. J. Clin. Nutr. 92:835-840.

Aguirre J.I., Gomar M.S., Igal S., Quiroga M.A., Portiansky E.L. \& Gimeno E.J. 2005. Bone changes caused by experimental Solanum malacoxylon poisoning in rabbits. Pesq. Vet. Bras. 25(1):34-38.

Auwerx J. \& Bouillon R. 1986. Mineral and bone metabolism in thyroid disease: A review. Quart. J. Med. 60:737-752.

Banovac K. \& Koren E. 2000. Triiodothyronine stimulates the release of membrane-bound alkaline phosphatase in osteoblastic cells. Calcif. Tissue Int. 67:460-465.

Barroga E.F., Kadosawa T., Okumura M. \& Fujinaga T. 2000. Inhibitory effects of 22-oxa-calcitriol and all-trans retinoic acid on the growth of a canine osteossarcoma derived cell-line in vivo and its pulmonary metastasis in vivo. Res. Vet. Sci. 68(1):79-87.

Barros S., Tabone E., Santos M., Andujar M. \& Grimaud J.A. 1981. Histopathological and ultrastructural alterations in the aorta in experimental Solanum malacoxylon poisoning. Virchows Arch. 35:169-175.

Barros S.S. \& Rosa F.G. 1999. Proliferação de macrófagos e células gigantes multinucleadas na mucosa bronquial e traqueal de coelhos experimentalmente intoxicados com Solanum glaucophyllum (S. malacoxylon). Anais 9o Enapave, Belo Horizonte, MG.

Barros S.S. 1989. Aspectos ultraestruturais da calcinose experimental induzida por plantas. Anais VII Encontro Médico-Universitário de Santa Maria, RS.

Barros S.S. 2011. Comunicação pessoal (Depto Patologia, Universidade de Santa Maria, RS).

Barros S.S. \& Gimeno E.J. 2000. Cell differentiation and bone protein synthesis in the lung of sheep with spontaneous calcinosis. J. Comp. Pathol. 123(4):270-277.

Barros S.S., Driemeier D., Santos M.N. \& Guerrero J.A.M. 1992. Evolução clínica e reversibilidade das lesões da calcinose enzoótica dos ovinos induzida por Nierembergia veitchii. Pesq. Vet. Bras. 12(1/2):5-10.

Barros S.S., Russowski D. \& Grando S.M. 1996. Ultra-estrutura das alterações ósseas na intoxicação experimental por Solanum malacoxylon em coelhos. Pesq. Vet. Bras.16(2/3):81-86.

Barros S.S., Soares M.P. \& Gimeno J. 2006. Macrophages and giant cell proliferation associated with bone protein synthesis and calcification in the trachea and bronchi of rabbits intoxicated with Solanum glaucophyllum. Vet. Pathol.43:494-499.

Berth-Jones J., Bourke J.F., Iqbal S.J. \& Hutchinson P.E. 1993. Urine calcium excretion during treatment of psoriasis with topical calcipotriol. Brit. J. Dermatol. 129(4):411-414.

Besch-Williford C., Matherne C. \& Wagner J. 1985. Vitamin D toxicosis in commercially reared rabbits. Lab. Anim. Sci. 35(5):528.

Bijslma J.W.J., Duursma A.S., Roelofs J.M.M. \& Der Kinderen P.J. 1983. Thyroid function and bone turnover. Acta Endocrinol. 104:42-49.

Bischoff-Ferrari H.A., Borchers M., Gudat F., Dümüller U., Stähelin H.B. \& Dick W. 2004. Vitamin D receptor expression in human muscle tissue decreases with age. J. Bone Miner. Res. 19(2):265-269.

Boon E.S. \& Cozijn D. \& Brombacher P.J. 1993. Enhanced production of calcitriol, and hypercalcaemia in a patient with sarcoidosis provoked by daily intake of calciol. Eur. J. Clin. Chem. Clin. Biochem. 31(10):679-681.

Braverman L.E. \& Utiger R.D. 1996. Werner and Ingbar's The Thyroid. $7^{\text {th }}$ ed. Lippncoutt-Raven, Philadelphia.

Buffenstein R., Laundy M.T., Pitcher T. \& Pettifor J.M. 1995. Vitamin D3 intoxication in naked mole-rats (Heterocephalus glaber) leads to hypercalcaemia and increased calcium deposition in teeth with evidence of abnormal skin calcification. Gen. Comp. Endocrinol. 99:35-40.
Burkhart J.M. \& Jowsey J. 1967. Parathyroid and thyroid hormones in the development of immobilization osteoporosis. Endocrinol. 81:10531062.

Cano A., Baum M. \& Moe O.W. 1999. Thyroid hormone stimulates the renal Na/H exchanger NHE3 by transcriptional activation. Am. J. Physiol. 276:102-108.

Capen C.C. \& Rosol T.J. 1996. Controle hormonal do metabolismo mineral, p.974-992. In: Bojrab M.J. (Ed.), Mecanismos da Moléstia na Cirurgia dos Pequenos Animais. $2^{\mathrm{a}}$ ed. Manole, São Paulo.

Castillo V.A. 2002. Excesso del iodo dietario sobre la funcion tiroidea y su relación com osteopatias metabólicas de presentación frecuente durante el crecimiento. Tese de Doutorado, Facultad de Ciências Veterinárias, Universidad de Buenos Aires.

Castillo V.A., Pisarev M.A., Lalia J.C., Rodriguez M.S., Cabrini R.L. \& Márquez G. 2001. Commercial diet induced hypothyroidism due to high iodine: A histological and radiological analysis. Vet. Quart. 23(4):218-223.

Ceglia L. 2008. Vitamin D and skeletal muscle tissue and function. Mol. Aspects Med. 29(6):407-414.

Chavhan S.G., Brar R.S., Banga H.S., Sandhu H.S., Sodhi S., Gadhave P.D., Kothule V.R. \& Kammon A.M. 2011. Clinicopathological studies on vitamin $\mathrm{D}_{3}$ toxicity and therapeutic evaluation of Aloe vera in rats. Toxicol. Int. 18(1):35-43.

Cheville N.F. 2004. Introdução a Patologia Veterinária. 2a ed. Roca, São Paulo, p.296.

Cho D.Y., Frey R.A., Guffy M.M. \& Leipold H.W. 1975. Hypervitaminosis in the dog. Am. J. Vet. Res. 36:1597-1603.

Cramer B., Husa L. \& Pushpanathan C. 1998. Nephrocalcinosis in rabbits: Correlation of ultrasound, computed tomography, pathology and renal function. Pediatr. Radiol. 28(1):9-13.

Cross H.S. \& Peterlik M. 1988. Calcium and inorganic phosphate transport in embryonic chick intestine: Triiodothyronine enhances the genomic action of 1,25-dihydroxycholecalciferol. J. Nutr. 118:1529-1534.

Cross H.S. \& Peterlik M. 1991. Differentiation-dependent expression of calcitriol actions on absorptive processes in cultured chick intestine: modulation by triiodothyronine. Acta Endocrinol., Copenh., 124:679-684.

Cumming C. 1991. Suspected vitamin D rodenticide poisoning in a dog. Vet. Rec. 22:600.

David L.W. 1991. The nutritional relationships of vitamin A. J. Orthomol. Med. 6(1):27-30.

Dawson-Hughes B. 1997. Vitamina D, p.1502-1503. In: Bennett J.C. \& Cecil P.F. (Eds), Tratado de Medicina Interna. Vol.2. $2^{\mathrm{a}}$ ed. Guanabara Koogan, Rio de Janeiro.

Dawson-Hughes B., Heaney R.P., Holick M.F., Lips P., Meunier P.J. \& Vieth R. 2005. Estimates of optimal vitamin D status. Osteoporosis Int. 16:713716.

De Luca H.F. 2004. Overview of general phisiologic features and functions of vitamin D. Am. J. Clin. Nutr. 80:1689-1696.

Döbereiner J., Tokarnia C.H., Costa J.B.D., Campos J.L.E. \& Dayrell M.S. 1971. "Espichamento", intoxicação de bovinos por Solanum malacoxylon no Pantanal de Mato Grosso. Pesq. Agropec. Bras. 6:91-117.

Done S.H., Döbereiner J. \& Tokarnia C.H. 1976. Systemic connective tissue calcification in cattle poisoned by Solanum malacoxylon: A histological study. Brit. Vet. J. 132:28-38.

Down P.F., Polak A. \& Regan R.J. 1979. A family with massive acute vitamin D intoxication. Postgrad. Med. J. 55(654):897-902.

Driemeier D., Cruz C.E.F., Gomes M.J.P., Corbellini L.G., Loretti A.P. \& Colodel E.M. 1999. Aspectos clínicos e patológicos da paratuberculose em bovinos no Rio Grande do Sul. Pesq. Vet. Bras. 19(3/4):109-115.

Eriksen E.F., Mosekilde L. \& Melsen F. 1986. Kinetics of trabecular bone resorption and formation in hypothyroidism: Evidence for a positive balance per remodeling cycle. Bone 7:101-108.

Ewan R.C. 1996. Vitaminas, p.59-88, 457-469. In: Swenson M.J. \& Reece W.O. (Eds). Dukes: Fisiologia dos Animais Domésticos. 11aㅡ ed. Guanabara Koogan, Rio de Janeiro. 
Feskanich D., Singh V., Willett W.C. \& Colditz G.A. 2002. Vitamin A intake and hip fractures among postmenopausal women. J. Am. Assoc. Med. 287:47-54.

Friedman W.F. \& Roberts W.C. 1966. Vitamin D and supravalvular aortic stenosis syndrome: The transplacental effects of vitamin D on the aorta of the rabbit. Am. Heart Assoc. Inc. Circulation 34:77-86.

Gomar M.S., Portiansky E.L., Dallorso M.E., Barros S.S., Costa E.F. \& Gimeno E.J. 2000. Diferenciacion celular y sintesis de proteinas oseas en aorta y pulmones inducidas por plantas calcinogenicas. Anais Taller Internacional de Toxicosis por Plantas en Animales y Humanos, La Habana, Cuba.

Granner D.K., Murray R.K., Granner D.K., Mayes P.A. \& Rodwell V.W. 1998. Hormônios que regulam o metabolismo do cálcio, p.539-546. In: Murray R.K., Granner D.K., Mayes P.A. \& Rodwell V.W. (Eds), Harper: Bioquímica: um livro Médico Lange. 8aㅡ ed. Atheneu, São Paulo.

Gu W.X., Stern P.H., Madison L.D. \& Du G.G. 2001. Mutual up-regulation of thyroid hormone and parathyroid hormone receptors in rat osteoblastic osteosarcoma 17/2.8 cells. Endocrinol. 142:157-164.

Hansen K.E. 2011. High-dose vitamin D: Helpful or harmful? Curr. Rheumatol. Rep. 13:257-264.

Hansen K.E., Jones A.N., Lindstrom M.J., Davis L.A., Engelke J.A. \& Schafer M.M. 2008. Vitamin D insufficiency: Disease or no disease? J. Bone Miner. Res. 23:1052-1060.

Haschek W.M., Krook L., Kallfelz F.A. \& Pond W.G. 1978. Vitamin D toxicity: Initial site and mode of action. Cornell Vet. 68(3):324-364.

Heaney R.P. 1996. Pathophysiology of osteoporosis. Am. J. Med.Sci. 312:251-256.

Heaney R.P., Dowell M.S., Hale C.A. \& Bendich A. 2003. Calcium absorption varies within the reference range for serum 25 -hydroxyvitamin D. J. Am. Coll. Nutr. 22:142-146.

Hillard T.C. \& Stevenson J.C. 1991. Role of estrogen in the development of osteoporosis. Calcif. Tissue Int. 1991;49:55-59.

Hofbauer L.C., Kühne C.A. \& Viereck V. 2004. The OPG/RANKL/RANK system in metabolic bone diseases. J. Musculoskelet. Neuronal Interact. 4(3):268-275.

Holick M.F. 2002. Vitamin D. Clin. Rev. Bone Min. Metabol. 1(3/4):181-207.

Holick M.F. 2004. Sunlight and vitamin D for bone health and prevention of autoimmune diseases, cancers, and cardiovascular disease. Am. J. Clin. Nutr. 80(6):1678-1688.

Holick M.F. 2005. The Vitamin D epidemic and its health consequences. J. Nutr. 135(11):2739-2748.

Holick M.F. 2007. Vitamin D deficiency. N. Engl. J. Med. 357:266:281.

Holick M.F., Maclaughlin J.A. \& Dopplet S.H. 1981. Regulation of cutaneous previtamin $\mathrm{D}_{3}$ photosynthesis in man: Skin pigment is not an essential regulator. Science 211:590-593.

Hoppe B., Gnehm H.E., Wopmann M., Neuhaus T., Willi U. \& Leumann E. 1992. Vitamin D poisoning in infants: A preventable cause of hypercalciuria and nephrocalcinosis. Schweiz. Med. Wochenschr. 122(8):257-262.

Islabão N. 1987. Vitaminas: seu metabolismo no homem e nos animais. $2^{\underline{a}}$ ed. Nobel, São Paulo. 201p.

Jiang Y., Wang Y., Zhao J., Marchal G., Wang Y., Shen Y., Xing S., Zhang X. \& Baert A.L. 1990. Metastatic calcification within bone: The main cause of osteosclerosis in hypervitaminosis $\mathrm{D}_{3}$, radiologic-pathologic correlation. Invest. Radiol. 25:1188-1196.

Jiang Y., Wang Y., Zhao J., Marchal G., Wang Y., Shen Y., Xing S., Li R. \& Baert A.L. 1991. Bone remodeling in hypervitaminosis D3: Radiology, microangiographic, pathologic correlations. Invest. Radiol. 26:213-219.

Jones T.C., Hunt R.D. \& King N.W. 2000. Patologia Veterinária. 6aa ed. Manole, São Paulo. p.65-67.

Jowsey J. \& Detenbeck L.C. 1969. Importance of thyroid hormones in bone metabolism and calcium homeostasis. Endocrinol. 85:87-95.

Kane A.B. \& Kumar V. 2005. Patologia nutricional e ambiental, p.433-489. In: Kumar V., Abbas A.K. \& Fausto N. (Eds), Robbins e Cotran's Patologia: bases patológicas das doenças. ${ }^{\mathfrak{a}} \stackrel{\mathrm{e}}{\mathrm{e}}$. Saunders Elsevier: Rio de Janeiro.
Kaneko J.J. 1997. Clinical Biochemistry of Domestic Animals. $5^{\text {th }}$ ed. Academic Press, San Diego. 932p.

Khosla S. 2001. Minireview: The OPG/RANKL/RANK System. Endocrinol. 142(12):5050-5055.

Kitazawa S., Kajimoto K., Kondo T. \& Kitazawa R. 2003. Vitamin $D_{3}$ supports osteoclastogenesis via functional vitamin $\mathrm{D}$ response element of human RANKL gene promoter. J. Cell. Biochem. 89(4):771-777.

Kochupillai N. 2008. The physiology of vitamin D: Current concepts. Indian J. Med. Res. 127:256-262.

Krook L., Belanger L.F., Henrikson P.A., Lutwak L. \& Sheffy B.E. 1970. Bone flow. Rev. Can. Biol. 29(2):157-167.

Lehmann B. \& Meurer M. 2003. Extrarenal sites of calcitriol synthesis: The particular role of skin. Recent Results Cancer Res. 164:135-145.

Long G.G. 1984. Acute toxicosis in swine associated with excessive dietary intake of vitamin D. J. Am. Vet. Med. Assoc. 184(2):164-170.

Malabanan A., Veronikis I.E. \& Holick M.F. 1998. Redefining vitamin D insufficiency. Lancet. 351:805-806.

Marcus R. 1996. Fármacos que afetam a calcificação e a renovação do osso: cálcio, fosfato, paratormônio, vitamina D3, calcitonina e outros compostos, p.1126-1146. In: Hardman J.G. \& Limbird L.E. (Eds), Goodman L. and Gilman: As Bases Farmacológicas da Terapêutica. Interamericana Editores 9aㅡ ed. McGraw-Hill, Rio de Janeiro.

Mayes P.A. 1998. Estrutura e função das vitaminas lipossolúveis, p.614624. In: Murray R.K., Granner D.K., Mayes P.A. \& Rodwell V.W. (Eds), Lange Harper - Um Livro Médico: bioquímica. 8 ${ }^{\mathrm{a}}$ ed. Atheneu, São Paulo.

McCollum E.V., Simmonds N., Shipley P.G. \& Park E.A. 1925. Studies on experimental rickets. XXVI. A diet composed principally of purified foodstuffs for use with the "Lina Test" for vitamin D studies. J. Biol. Chem. 65:97-100.

McGavim M.D. \& Zachary J.F. 2007. Pathologic Basis of Veterinary Disease. $4^{\text {th }}$ ed. Mosby Elsevier, St Louis, Missouri. p.144-146.

Mellanby R.J., Mee A.P., Berry J.L. \& Herrtage M.E. 2006. Hypercalcaemia in two dogs caused by excessive dietary supplementation of vitamin D. J. Small Anim. Pract. 46(7):334-338.

Mello J.R.B. \& Habermehl G. 1995. Substâncias com atividade similar à vitamina $\mathrm{D}_{3}$ em quatro plantas calcinogênicas. Pesq. Vet. Bras.15(2/3):7378

Mello J.R.B., Langeloh A., Habermehl G., Krebs H.C. \& Bastos F.C. 1999. Influência da administração de extratos de duas plantas calcinogênicas sobre a fertilidade de ratos. Arq. Bras. Med. Vet. Zootec. 51(5):453-462.

Metz A.L., Walser M.M. \& Olson W.G. 1985. The interaction of dietary vitamin A and D related to skeletal development in the turkey poult. J. Nutr. 115:929-935.

Michaëlsson K., Lithell H., Vessby B. \& Melhus H. 2003. Serum retinol levels and risk of fracture. N. Engl. J. Med. 348:287-294.

Miura M., Kiyoshi T., Komatsu Y., Suda M., Yasoda A., Sakuma Y., Osaza A. \& Nakao K. 2002. A novel interaction between thyroid hormones and 1,25(OH)2D3 in osteoclast formation. Biochem. Biophys. Res.Commun. 291:987-994.

Molina H., Mena P., Vial P., Fernandez M.E., Alcazar M.L. \& Muzzo S. 1984. Intoxicación por Vitamina D en el Lactante. Revta Chil. Pediatr. 55(4):270-273.

Moraña J.A., Barros S.S., Driemeier D. \& Flôres Y.E. 1994. Gastropatia em coelhos experimentalmente induzida pela planta calcinogênica Solanum malacoxylon. Pesq. Vet. Bras. 14:35-42.

Morita T., Awakura T., Shimada A., Umemura T., Nagai T. \& Haruna A. 1995. Vitamin D toxicosis in cats: Natural outbreak and experimental study. J. Vet. Med. Sci. 57(5):831-837.

Mosekilde L. \& Melsen F. 1978. Morphometric and dynamic studies of bone changes in hypothyroidism. Acta Pathol. Microbiol. Scand. 86:5662.

Mosekilde L., Eriksen E.F. \& Charles P. 1990. Effects of thyroid hormones on bone and mineral metabolism. Endocrinol. Metab. Clin. North Am. 19:35-63. 
Okawa H., Doi K., Yasoshima A., Fujita T. \& Okaniwa A. 1980. Pathology of experimental atherosclerosis: Changes of acute phase in rats loaded with vitamin $\mathrm{D}_{2}$ and cholesterol. Japn. J. Vet. Sci. 42:623-633.

Parfitt M.A. 1977. The cellular basis of bone turnover and bone loss. Clin. Orthoped. Relat. Res. 127:236-247.

Pedrosa M.A.C. \& Castro M.L. 2005. Papel da vitamina D na função neuromuscular. Arq. Bras. Endocrinol. Metabol. 49(4):495-502.

Peixoto P.V., Klem M.A.P., Brito M.F., Cerqueira V.D. \& França T.N. 2010. Aspectos toxicológico, clínico-patológico e ultra-estrutural das intoxicações iatrogênica e experimental por vitamina D em coelhos. Pesq. Vet. Bras. 30(3):277-288.

Peterson E.N., Kirby R., Sommer M. \& Bovee K.C. 1991. Cholecalciferol rodenticide intoxication in a cat. J. Am. Vet. Med. Assoc. 199(7):904-906.

Pfeifer M., Begerow B. \& Minne H.W. 2002. Vitamin D and muscle function. Osteoporosis Int. 13(3):187-194.

Qiao S., Pennanen P., Nazarova N., Lou Y.R. \& Tuohimaa P. 2003. Inhibition of fatty acid synthase expression by 1 alpha, 25-dihydroxyvitamin D3 in prostate cancer cells. J. Steroid Biochem. Mol. Biol. 85(1):1-8.

Rambeck W.A., Strohle H.G., Wetzel A. \& Zucker H. 1981. Calcinogenic activity of vitamin D3 and vitamin D3 palmitate in rat and rabbit. Int. J. Nutr. Res. 51(4):359-364.

Raisz L.G. 1999. Physiology and pathophysiology of bone remodeling. Clin. Chem. 45:1353-1358.

Rohde C.M., Manatt M., Clagett-Dame M. \& DeLuca H.F. 1999. Vitamin A antagonizes the action of vitamin D in rats. J. Nutr 129:2246-2250.

Ribeiro AFC. 2002. Relação tireóide-gônadas no osso e na histomorfometria das paratireóides de ratas adultas hipotireóideas castradas. Dissertação de Mestrado em Medicina Veterinária, Escola de Veterinária, UFMG, Belo Horizopnte. 55p.

Riet-Correa F., Méndez M.D.C., Schild A.L. \& Petiz C.A. 1993. Enzootic calcinosis in sheep: Experimental reproduction with Nierembergia veitchii (Solanaceae). Pesq. Vet. Bras.13(1/2):21-24.

Riet-Correa F., Méndez M.D.C., Schild A.L., Santos E.C. \& Scarsi R.M. 1981. Experimentos em coelhos sugerem Nierembergia veitchii como causa de calcinose enzoótica em ovinos do Rio Grande do Sul. Pesq. Agropec. Bras. 16(5):727-732.

Rissi D.R., Rech R.R., Pierezan F., Kommers G.D. \& Barros C.S.L. 2007. Intoxicação em ovinos por Nierembergia veitchii: observações em quarto surtos. Ciência Rural 37(5):1393-1398.

Ross P.D. 1996. Prediction of fracture risk II: Other risk factors. Am. J. Med. Sci. 312:260-269.

Sanders K.M., Stuart A.L., Williamson E.J., Simpson J.A., Kotowicz M.A., Young D. \& Nicholson G.C. 2010. Annual high-dose oral vitamin D and falls and fractures in older women: A randomized controlled trial. J. Am. Med. Assoc. 303:1815-1822.

Santos C.E.P., Pescador C.A., Ubiali D.G., Colodel E.M., Souza M.A., Silva J.A., Canola J.C. \& Marques L.C. 2011. Intoxicação natural por Solanum glaucophyllum (Solanaceae) em búfalos no Pantanal Matogrossense. Pesq. Vet. Bras. 31(12):1053-1058.

Seawright A.A., Steele D.P. \& Clark L. 1968. Hypervitaminosis A of cats in Brisbane. Aust. Vet. J. 44(5):203-206.
Seifert G. \& Henting O.V. 1967. Histochemische und elektronisch-optische Befunde zur Pathogenese der experimentellen Hautkalzinose. Beitrag Pathol. Anatom. 135:75-91.

Serakides R. 2001. Relação tireóide, gônadas e metabolismo ósseo em ratas adultas hipertireóideas e eutireóideas. Tese de doutorado em Ciência Animal, Escola de Veterinária, UFMG, Belo Horizonte. 90p.

Silva C.A.M., Merkt H., Bergamo P.N.L., Barros S.S., Barros C.S.L., Santos M.N., Hoppen H.O., Heidemann P. \& Meyer H. 1987. Consequence of excess iodine supply in a Thoroughbred stud in southern Brazil. J. Reprod. Fert. 35:529-533.

Singh S.K. \& Prasad M.C. 1989. Vitamin D induced arteriosclerosis in goats. Indian J. Anim. Sci. 59(9):1114-1117.

Singh S.K. \& Prasad M.C. 1990. Pathology of hypervitaminosis D in goats: An experimental study. Indian J. Anim. Sci. 60(3):295-301.

Spangler W.L., Gribble D.H. \& Lee T.C. 1979. Vitamin D intoxication and the pathogenesis of vitamin D nephropathy in the dog. Am. J. Vet. Res. 40(1):73-83.

Stehbens W.E. 1988. Localization of experimental calcification in rabbit blood vessels with particular reference to hemodynamics. Angiology 39(7)597-608.

Stevenson R.G., Palmer N.C. \& Finley G.G. 1976. Hipervitaminosis D in rabbits. Can. Vet. J. 17:54-57.

Thomas J.B., Hood J.C. \& Gaschk F. 1990. Cholecalciferol rodenticide toxicity in a domestic cat. Aust. Vet. J. 67(7):274-275.

Thompson K. 2008. Bones and joints, p.1-184. In: Maxie M., Jubb K.V.F., Kennedy P.C. \& Palmer N.C. (Eds), Patology of Domestic Animals. Vol.1. $15^{\text {th }}$ ed. Saunders Elsevier, Toronto.

Toda T., Leszczynski D.E. \& Kummerow F.A. 1983. The role of 25-hydroxyvitamin D3 in the induction of atherosclerosis in swine and rabbit by hypervitaminosis D. Acta Pathol. Japn. 33(1):37-44.

Tokarnia C.H., Döbereiner J. \& Peixoto P.V. 2000. Plantas Tóxicas do Brasil. Editora Helianthus, Rio de Janeiro, p.188-196.

Varga F., Rumpler M., Luegmayr E., Fratzl-Zelman N., Glantschning K. \& Klaushofer K. 1997. Triiodothyronine, a regulator of osteoblastic differentiation: Depression of histone H4, attenuation of c-fos/c-jun, and induction of osteocalcin expression. Calcif. Tissue Int. 61:404-411.

Wagner N., Wagner K.D., Schley G., Badiali L., Theres H. \& Scholz H. 2003. 1,25-dihydroxyvitamin $\mathrm{D}_{3}$-induced apoptosis of retinoblastoma cells is associated with reciprocal changes of Bcl-2 and bax. Exp. Eye Res. $77(1): 1-9$

Wang J.C. 1992. In vitro effect of 1,25-dihydroxyvitamin $\mathrm{D}_{3}$ on proliferation and collagen synthesis by bone marrow fibroblasts. Acta Haematol. 88(1):27-31.

Werner P.R. 2010. Patologia Geral Veterinária Aplicada. Editora Roca, São Paulo. 384p.

Zimmerman T.E., Giddens Jr W.E., DiGiacomo R.F. \& Ladiges W.C. 1990. Soft tissue mineralization in rabbits fed a diet containing excess vitamin D. Lab. Anim. Sci. 40(2):212-215.

Zittermann A. 2006. Vitamin D and disease prevention with special reference to cardiovascular disease. Progr. Biophys. Mol. Biol. 92(1):3948. 